\title{
EFEITO DO ÁCIDO SALICÍLICO NA FORMAÇÃO DE MICORRIZAS ARBUSCULARES E NAS ATIVIDADES DE QUITINASES E $\beta$-GLICANASES EM RAÍZES FEIJOEIRO
}

\author{
Heron Salazar Costa \\ Engenheiro Agrônomo
}

Orientador: Prof. Dr. MARCIO RODRIGUES LAMBAIS

Dissertação apresentada à Escola Superior de Agricultura "Luiz de Queiroz", Universidade de São Paulo, para obtenção do título de Mestre em Agronomia. Área de concentração: Microbiologia Agrícola.

PIRACICABA

Estado de São Paulo - Brasil

Dezembro - 1998 
Dados Internacionais de Catalogação na Publicação (CIP) DIVISÃO DE BIBLIOTECA E DOCUMENTAÇÁO - Campus "Luiz de Queiroz"/USP

Costa, Heron Salazar

Efeito do ácido salicilico na formação de micorrizas arbusculares e nas atividades de quitinases e $\beta$-1,3 glicanases em raízes de feijoeiro / Heron Salazar Costa. - - Piracicaba, 1998.

52p. : il.

Dissertação (mestrado) - - Escola Superior de Agricultura Luiz de Queiroz, 1998. Bibliografia.

1. Ácido salicilico 2. Beta-glucanase 3. Feijāo 4. Fosfato 5. Fungo micorrízico 6. Micorriza 7. Proteção 8. Quitinase 8. Raiz I. Título

CDD 635.652 
Ofereço,

A Deus, senhor de todas as coisas, que tudo me permitiu e me fez filho de Rogélia Salazar da Silva, meu maior exemplo de amor aos filhos, e assim, fazer parte de uma família tão maravilhosa.

A todos meus familiares,

Dedico 


\section{AGRADECIMENTOS}

Ao Prof. Marcio Rodrigues Lambais, pela orientação, apoio e amizade.

Aos técnicos do Laboratório de Microbiologia do Solo: Denise Lourdes Colombo Mescolotti e Luis Fernando Baldesin, pela ajuda durante toda a fase do curso, auxílio nos trabalhos práticos e sobretudo, pela amizade;

À prof Elke Jurandy Bran Nogueira Cardoso, pelo apoio, amizade e ensinamentos.

À coordenação do Curso de Pós-Graduação em Microbiologia Agrícola, nas pessoas do prof. Dr. Luiz Gonzaga Prado Filho, coordenador na época de meu ingresso, e do prof. Dr. Flávio César A. Tavares, atual coordenador

A todos os professores com os quais em algum dia tive contato acadêmico e a todos funcionários dos departamentos que de uma forma ou outra me ajudaram;

À Coordenação de Aperfeiçoamento de Pessoal de Nível Superior CAPES, pela bolsa de estudo.

Ao serviço social na pessoa de Solange C. do Couto pelo auxílio moradia, uma grande ajuda que em muito contribuiu para que eu tivesse condições financeiras para terminar o curso.

À Helaine Carrer e Regina Monteiro, pelas sugestões no texto desse trabalho.

Especialmente a Marco Antônio Nogueira, pela contribuição na revisão do texto. 
LISTA DE ABREVIATURAS ................................................................ i

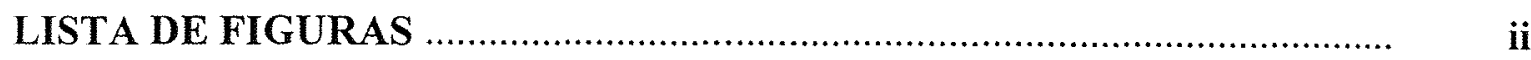

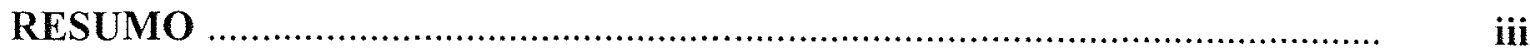

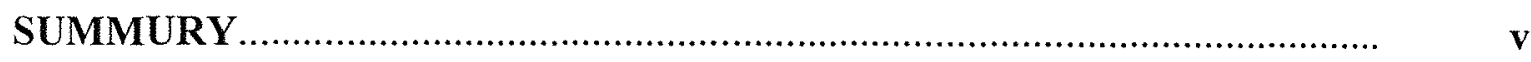

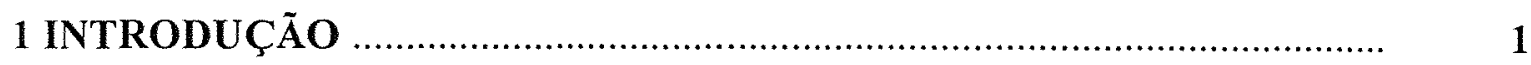

2 REVISÃO DE LITERATURA ……...................................................... 3

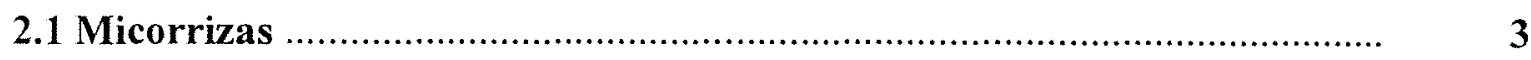

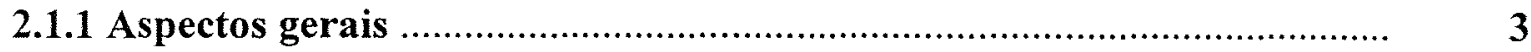

2.1.2 $\mathrm{O}$ estabelecimento das micorrizas arbusculares ........................................... 5

2.1.3 Reações de defesa vegetal em micorrizas arbusculares ...............................

2.1.4 Atividades de quitinases e $\beta$-1,3-glucanases em micorrizas

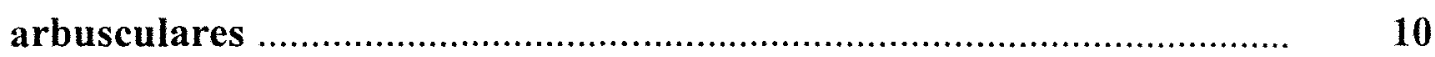

$2.2 \mathrm{O}$ envolvimento do ácido salicílico nas reações de defesa vegetal ................. 12

3. MATERIAL E MÉTODOS ….................................................................. 14

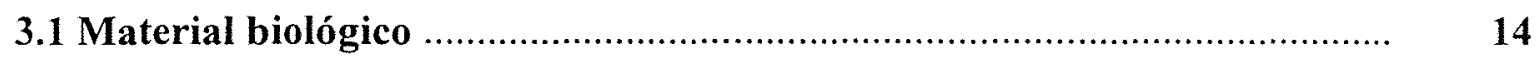

3.2 Montagem, condições de cultivo e procedimentos de colheita ..................... 14

3.2.1 Preparação do substrato, plantio e inoculação …………………............... 14

3.2.2 Condução, condições de cultivo e colheita ……………………................ 15

3.3 Avaliação do nível de colonização micorrízica ………................................. 17

3.4 Extrạ̧ão e quantificação de proteínas ......................................................... 17

3.5 Determinação das atividades de quitinases ................................................. 18

3.6 Determinação das atividades de $\beta-1,3$-glicanases .......................................... 19 
3.7 Delineamento, unidade experimental e análises estatísticas

4 RESULTADOS E DISCUSSÃO ……………............................................. 21

4.1 Efeito sobre a produção de biomassa vegetal .............................................. 21

4.2 Efeito sobre o nível de colonização micorrízica ................................................ 23

4.3 Efeito sobre as atividades de quitinases ...................................................... 26

4.4 Efeito sobre as atividades $\beta$-1,3-glicanases .................................................. 29

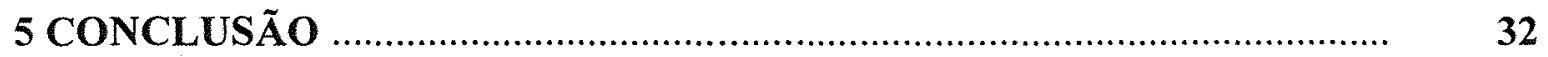

REFERÊNCIAS BIBLIOGRÁFICAS ….................................................. 33

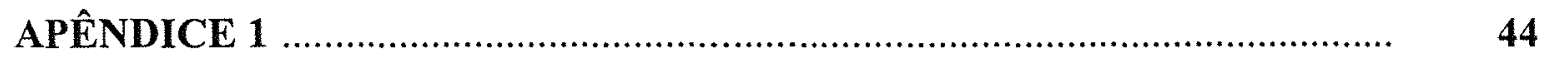

APÊNDICE 2 …........................................................................ $\quad 5$ 


\section{LISTA DE ABREVIATURAS}

AS: Ácido salicílico

CHI: Chalcona isomerase

ddi: Destilada deionizada

EAOs: Espécies ativas de oxigênio

FAL: Fenilalanina amônia liase

FMAs: Fungos micorrízicos arbusculares

Gi: Glomus intraradices

Gc: Glomus clarum

MAs: Micorrizas arbusculares

MSPA: Matéria seca da parte aérea

NC: nível de colonização

Ni: não inoculado

PMSF: Fluoreto de metanolsufonil

SAP: Semanas após o plantio

SR: Sistema radicular 


\section{LISTA DE FIGURAS}

1 Matéria seca da parte aérea (MSPA) de feijoeiros não-inoculados ou inoculados com Glomus clarum (Gc) ou Glomus intraradices (Gi), em condições de baixo (20 $\mathrm{mg} \mathrm{L}^{-1}$ de substrato) ou alto $\mathrm{P}$ (150 $\mathrm{mg} \mathrm{L}^{-1}$ de substrato). A. Sem aplicação de ácido salicílico. B. Com aplicação de ácido salicílico $(7,24 \mu \mathrm{mol}$ a cada 2 dias, a partir de duas semanas após o plantio). Os dados são médias de 4 repetições \pm desvio padrão da média

2 Porcentagem de colonização de raízes de feijoeiro inoculadas com Glomus clarum $(O, \bullet)$ ou Glomus intraradices $(\square, \mathbf{(})$, em condições de baixo $\left(20 \mathrm{mg} \mathrm{L}^{-1}\right.$ de substrato;O, $\square)$ ou alto P (150 $\mathrm{mg} \mathrm{L}^{-1}$ de substrato; e, E). A. Sem aplicação de ácido salicílico. B. Com aplicação de ácido salicílico $(7,24 \mu \mathrm{mol}$ a cada 2 dias, a partir de duas semanas após o plantio). Os dados são médias de 4 repetições \pm desvio padrão da média.

3 Atividades específicas de quitinases em raízes de feijoeiros não-inoculadas ou inoculadas com Glomus clarum (Gc) ou Glomus intraradices (Gi), em condições de baixo ( $20 \mathrm{mg} \mathrm{L}^{-1}$ de substrato) ou alto $\mathrm{P}$ (150 $\mathrm{mg} \mathrm{L}^{-1}$ de substrato). A. Sem aplicação de ácido salicílico. B. Com aplicação de ácido salicílico $(7,24 \mu \mathrm{mol}$ a cada 2 dias, a partir de duas semanas após o plantio). Os dados são apresentados em Unidades de Absorbância à $550 \mathrm{~nm}\left(\mathrm{UA}_{550}\right)$ por mg de proteína por hora, e são médias de 4 repetições \pm desvio padrão da média.

4 Atividades específicas de $\beta$-1,3-glicanases em raizes de feijoeiros não-inoculadas ou inoculadas com Glomus clarum (Gc) ou Glomus intraradices (Gi), em condições de baixo (20 $\mathrm{mg} \mathrm{L}^{-1}$ de substrato) ou alto $\mathrm{P}$ (150 $\mathrm{mg} \mathrm{L}^{-1}$ de substrato). A. Sem aplicação de ácido salicílico. B. Com aplicação de ácido salicílico $(7,24 \mu \mathrm{mol}$ a cada 2 dias, a partir de duas semanas após o plantio). Os dados são apresentados em Unidades de Absorbância à $600 \mathrm{~nm}\left(\mathrm{UA}_{600}\right)$ por mg de proteína por hora, e são médias de 4 repetições \pm desvio padrão da média 


\section{EFEITO DO ÁCIDO SALICÍlICO NA FORMAÇÃO DE MICORRIZAS ARBUSCULARES E NAS ATIVIDADES DE QUITINASES E $\beta$-1,3- GLICANASES EM RAÍZES DE FEIJOEIRO}

Autor: Eng. Agrônomo Heron Salazar Costa Orientador: Prof. Dr. Marcio Rodrigues Lambais

\section{RESUMO}

Os mecanismos que controlam o processo de colonização intrarradicular por fungos micorrízicos arbusculares ainda não são conhecidos, mas podem envolver o sistema de defesa vegetal. Normalmente, em condições favoráveis à formação de micorrizas arbusculares (MAs), e.g. baixo fosfato (P), ocorre supressão da expressão de genes de defesa, como quitinases e $\beta$-1,3-glicanases, em certos estágios do desenvolvimento das MAs. Assim, a inibição do crescimento fúngico intrarradicular em condições de alto $\mathrm{P}$ pode ser decorrência da atenuação da supressão e/ou indução de genes de defesa específicos. Se o sistema de defesa está envolvido no controle do crescimento fúngico intrarradicular em condições de alto $\mathrm{P}$, a aplicação às raízes de um indutor de respostas de defesa, como o ácido salicílico (AS), poderia simular o efeito inibitório do P. Este trabalho teve por objetivo avaliar o efeito do AS na colonização intrarradicular e nas atividades de quitinases e $\beta$-1,3-glicanases em raízes de feijoeiro (Phaseolus vulgaris L. var. Carioca 80-SH) inoculadas com Glomus clarum ou Glomus intraradices, em condições de baixo e alto $\mathrm{P}$.

Em condições de baixo P, a aplicação de AS inibiu a colonização intrarradicular à níveis similares aos observados em condições de alto $\mathrm{P}$. Em condições de alto $\mathrm{P}$, a inibição da micorrização pelo AS foi ainda maior. Associado à essa inibição, incrementos de aproximadamente 10 vezes nas atividades específicas de quitinases e redução nas atividades de $\beta$-1,3-glicanases nas raizes das plantas que receberam AS foram observados. Em função dos padrões de atividades de quitinases e $\beta$-1,3-glicanases 
nas raízes não-inoculadas e inoculadas, não foi possível estabelecer uma relação entre as atividades dessas hidrolases e crescimento fúngico intrarradicular. 


\section{EFFECTS OF SALICYLIC ACID ON ARBUSCULAR MYCORRHIZAE FORMATION AND ON CHITINASE AND $\beta$-1,3-GLUCANASE ACTIVITIES IN BEAN ROOTS}

Author: Eng. Agrônomo Heron Salazar Costa

Adviser: Prof. Dr. Marcio Rodrigues Lambais

\section{SUMMARY}

The mechanisms controlling intraradical colonization by arbuscular mycorrhizal fungi are not yet know but may involve the plant defense system. Normally, under appropriate conditions for mycorrhiza formation, e.g. low phosphate ( $\mathrm{P})$, the expression of plant defense genes, such as chitinases and $\beta-1,3$-glucanases, is suppressed. Under high $\mathrm{P}$ conditions, the inhibition of intraradical fungal growth may be due to an attenuation of suppression and/or induction of specific plant defense genes. If the plant defense system limits intraradical fungal growth under high $\mathrm{P}$ conditions, then the application to the roots of a plant defense inducer, such as salicylic acid (SA), might have the same effect as high P. The aim of this work was to evaluate the effects of SA on the intraradical colonization and on the activities of chitinases and $\beta-1,3$-glucanases in bean (Phaseolus vulgaris L. cv. Carioca 80-SH) roots inoculated with Glomus clarum or Glomus intraradices, and grown under low or high $\mathrm{P}$ conditions.

Under low $\mathrm{P}$, the application of SA to bean roots resulted in inhibition of intraradical fungal colonization to the levels observed under high $\mathrm{P}$ conditions. This inhibition was even greater under high P conditions. Associated with the inhibition of root colonization, a 10 -fold increase in chitinase and reduction of $\beta-1,3$-glucanase activities were observed in roots that received SA. Based on the patterns of chitinase and $\beta$-1,3-glucanase activities in not-inoculated and inoculated roots, it was not possible to 
establish a relationship between activities of these hidrolases and intraradical fungal growth. 


\section{INTRODUÇÃO}

Micorrizas arbusculares são associações simbióticas mutualísticas com enorme potencial de uso agrícola, pois são formadas pela maioria das plantas vasculares em associação com fungos da ordem Glomales, e apresentam várias vantagens em relação à plantas não colonizadas.

De modo simplificado, pode-se dizer que o estabelecimento de uma micorriza arbuscular resulta da interação entre as características da planta e do fungo. Uma vez que ambos componentes são influenciados pelas condições do meio, o resultado da interação também dependerá de fatores ambientais.

A disponibilidade de fosfato assimilável pela planta é uma das variáveis ambientais mais influentes sobre as micorrizas arbusculares. Tem sido constatado que altas concentrações de fosfato na planta são inibitórias à colonização intrarradicular por fungos micorrízicos arbusculares. No entanto, não se sabe quais os mecanismos fisiológicos envolvidos no controle do nível de colonização.

Em última análise, o grau de compatibilidade de uma associação simbiótica é determinado por grupos específicos de genes. Nas associações parasíticas, a compatibilidade entre parasita e hospedeiro resulta da interação dos produtos da expressão dos genes de virulência ou avirulência por parte do patógeno e de resistência ou susceptibilidade por parte do hospedeiro. Em micorrizas arbusculares, ainda não se sabe quais os mecanismos genéticos que controlam o seu desenvolvimento. No entanto, presume-se que isso ocorra pela interação de diferentes vias de transdução de sinais envolvidas na regulação (indução e/ou supressão) de genes relacionados com as reações de defesa vegetal. Já foi observado que as atividades de quitinases (EC 3.2.1.14) e $\beta$-1,3glicanases (EC 3.2.1.39) apresentam regulação espacial e temporal diferenciada em 
raízes colonizadas por fungos micorrízicos arbusculares em relação a raízes não colonizadas. Já se sabe também que tal regulação pode ser influenciada pelo nível de fosfato na planta.

O ácido salicílico é um composto fenólico produzido naturalmente pelas plantas, o qual atua na regulação da expressão de genes tipicamente induzidos durante a infecção por patógenos e no fenômeno de resistência sistêmica adquirida. Como efeito de sua aplicação na parte aérea de plantas, já foi observado redução da atividade de catalases, aumento da concentração de espécies ativas de oxigênio e indução da síntese de proteínas defesa vegetal, tais como quitinases, e $\beta$-1,3-glicanases. Contudo, o efeito do AS sobre a expressão de genes de defesa no sistema radicular ainda não foi determinado. Além disso, a maioria dos estudos sobre o papel do AS nas interações plantamicrorganismos foram feitos em sistemas patogênicos, e pouco se sabe sobre sua atuação durante a formação das micorrizas arbusculares.

Considerando-se que a inibição da formação de micorrizas arbusculares por altas concentrações de fosfato possivelmente envolva a ativação de genes defesa vegetal e que o AS atua como indutor da expressão desses genes, é provável que, na presença de AS e em condições de baixo P, o desenvolvimento de micorrizas arbusculares seja inibido de maneira similar ao que ocorre em condições de alto $P$, e se quitinases e $\beta$-1,3-glicanases estão envolvidas no controle do crescimento fúngico intrarradicular, seus padrões de expressão devem ser semelhantes.

Para testar essa hipótese, foram comparados os padrões de atividades de quitinases e $\beta-1,3$-glicanases no sistema radicular de feijoeiro não colonizados ou colonizados por Glomus intraradices e G. clarum em condições de baixo ou alto nível de fosfato, com e sem aplicação de AS. 


\section{REVISÃO DE LITERATURA}

\subsection{Micorrizas}

\subsubsection{Aspectos gerais}

A associação entre fungos miceliais com raízes de plantas superiores já era conhecida antes de 1885 , quando o termo micorriza foi usado a primeira vez, pelo botânico alemão Albert Bernard Frank (Harley \& Smith, 1983; Isaac, 1992). Com o reconhecimento da importância ecológica desse fato, o termo tornou-se universal para designar as associações simbióticas mutualísticas entre algumas espécies de fungos e a grande maioria das plantas vasculares ( Harley \& Smith, 1983; Siqueira \& Franco, 1988).

De acordo com as diferenças morfológicas resultantes da colonização inter e/ou intracelular do tecido radicular das plantas pelas diferentes espécies de fungos micorrízicos, definiu-se dois tipos básicos de micorrizas: ecto e endomicorrizas.

As ectomicorrizas são formadas por fungos basidiomicetos, e por alguns ascomicetos, que se associam com raizes de plantas das familias Pinaceae, Fagaceae, Betulaceae e Myrtaceae, que ocorrem normalmente em regiões de clima temperado. As raízes colonizadas por fungos ectomicorrízicos se caracterizam pela ramificação dicotômica e maior diâmetro, podendo também ocorrer mudança na coloração. Essas alterações são acompanhadas da formação de um manto micelial sobre a superfície radicular e de um emaranhado de hifas entre as células corticais (rede de Hartig), porém, não há penetração intracelular (Isaac, 1992; Tinker et al., 1992). Esses tipos de micorrizas ocorrem em cerca de $5 \%$ das espécies de plantas, tendo importância econômica principalmente em espécies florestais (Isaac, 1992; Molina et al., 1992). 
As endomicorrizas caracterizam-se pela colonização intracelular e ausência de modificações morfológicas visíveis nas raízes das plantas hospedeiras (Harley \& Smith, 1983; Bonfante-Fasolo, 1984). Elas podem apresentar estruturas típicas que as diferenciam. Certas endomicorrizas apresentam estruturas que se assemelham às ectomicorrizas, e por isso são denominadas ectendomicorrizas. Algumas endomicorrizas ocorrem somente em determinados grupos de plantas, como por exemplo, as da ordem Ericales. De acordo com o sub-grupo taxonômico da planta hospedeira, essas ectomicorrizas podem ser diferenciadas em: 1) ericóides - formadas na sua grande maioria por basidiomicetos e representantes das subfamilias Ericoideae, Rhododentroideae e Vaccinioideae, e gêneros das famílias Epachridaceae e Empetraceae; 2) arbutóides - formadas por basidiomicetos e membros das Arbutoideae e Pyrolaceae; 3) monotropóides - formadas pela associação de basidiomicetos com membros da família Monotropaceae. As orquídeas, em associação exclusiva com basidiomicetos, também formam um grupo diferenciado de endomicorrizas, as orquidaceas (Isaac, 1992; Siqueira, 1986; Tester et al., 1987).

As micorrizas arbusculares (MAs) são consideradas o tipo mais importante de endomicorrizas, pois ocorrem em mais de $80 \%$ das espécies vegetais conhecidas e nos mais variados ecossistemas (Molina, et al., 1992; Tester et al., 1987). Elas são formadas pela associação entre as raízes das plantas vasculares e fungos zigomicetos da ordem Glomales (Harley \& Smith, 1983). Aparentemente, não apresentam especificidade hospedeira (Bonfante-Fasolo, 1984; Hayman, 1983; Harley \& Smith, 1983). Existem aproximadamente 160 espécies de fungos micorrízicos arbusculares (FMAs), os quais pertencem a uma das três famílias atualmente aceitas: Glomaceae Pirozynski \& Dalpe; Acaulosporaceae Morton \& Benny; Gigasporaceae Gerd. \& Trappe (Bentivenga \& Morton, 1994; Simon et al., 1993). Os fungos colonizam intercelularmente o tecido cortical e diferenciam-se intracelularmente em estruturas típicas, chamadas arbúsculos. No entanto, não colonizam meristemas e nem tecidos vasculares. Os arbúsculos resultam da ramificação dicotômica das extremidades das hifas intracelulares e são envolvidos pela membrana plasmática da célula vegetal (Bonfante-Fasolo, 1984; 1992). Os 
arbúsculos são sítios da troca bidirecional de nutrientes entre os simbiontes (BonfanteFasolo, 1984; Smith \& Gianinazzi-Pearson, 1988; Smith \& Smith, 1990). Na grande maioria das vezes, tal associação traz beneficios mútuos, caracterizando uma associação simbiótica mutualística (Ahmadjian \& Paracer, 1986). Porém, em alguns casos, como em condições de alto nível de $\mathrm{P}$ no solo, as plantas podem ter seu desenvolvimento prejudicado devido a presença dos FMAs, caracterizando um parasitismo (Antunes \& Cardoso, 1991; Baas \& Lambers, 1988).

A maior absorção de água e de nutrientes pouco móveis no solo, como $\mathrm{P}, \mathrm{Cu}, \mathrm{e}$ $\mathrm{Zn}$, são apontadas como vantagens das plantas micorrizadas em relação às não micorrizadas (Gerdemann, 1968; Marschner, 1992; Smith \& Gianinazzi-Pearson, 1988). Outras vantagens são: diminuição da toxidez por manganês (Pacovsky, 1986), e maior resistência às doenças (Pflefeger \& Linderman, 1994). Todos esses benefícios apontados têm justificado os estudos para entendimento dos mecanismos de regulação das MAs, os quais poderão resultar em um melhor manejo e aproveitamento dessas simbioses na agricultura.

\subsubsection{O estabelecimento das micorrizas arbusculares}

O desenvolvimento das MAs pode ser dividido nas seguintes fases: pré-infecção, infeç̧ão e colonização.

A fase de pré-infecção reúne os eventos que ocorrem antes da penetração do fungo no tecido hospedeiro (germinação de esporos, crescimento das hifas germinativas, diferenciação de apressório) (Isaac, 1992).

Por serem biotróficos obrigatórios, os FMAs devem manter-se em associação com a planta hospedeira, do contrário não sobrevivem (Harley \& Smith, 1983). Seu crescimento no solo, na ausência de hospedeiro, é extremamente limitado. Portanto, é necessário que ocorra a penetração no tecido radicular para sua sobrevivência (Friese \& Allen, 1991). 
A germinação de esporos é uma etapa fundamental para o estabelecimento das MAs, no entanto não é condição sine qua non, uma vez que a hifa infectiva pode originar-se de outros propágulos que estejam próximo à raiz, sejam fragmentos de hifa, fragmentos de raízes infectadas ou mesmos vesículas (Harley \& Smith, 1983; Friese \& Allen, 1991 ).

Os compostos de origem vegetal podem ter efeitos diversos sobre o processo de estabelecimento das MAs. Plantas não-hospedeiras podem excretar compostos inibitórios à germinação de esporos e crescimento do tubo germinativo (Bécard \& Piché, 1989; Gianinazzi-Pearson et al., 1989; Glenn et al., 1985), enquanto que plantas hospedeiras podem excretar compostos indutores (Azicón \& Ocampo, 1981; Bécard \& Piché, 1989; Tsai \& Phillips 1991). O fato de se obter germinação e crescimento do tubo germinativo em meio água-agar indica que esses compostos não são essenciais para esses processos (Paula et al., 1989). Como exemplo, foi observado por Bécard \& Piché (1989) que exsudados de raízes de cenoura transformadas interagem sinergisticamente com $\mathrm{CO}_{2}$, estimulando a germinação e o alongamento de hifas. Posteriormente, foi identificado que quercetina, um flavonol, estimula o crescimento da hifa germinativa de Gigaspora margarita na presença de $2 \%$ de $\mathrm{CO}_{2}$ (Bécard et al., 1992). Em estudos mais detalhados, Bécard et al. (1995) sugeriram que compostos fenólicos não são essenciais para a germinação e alongamento das hifas, mas podem apenas contribuir favoravelmente. Giovannetti et al. (1996) também observaram, em meio estéril, que compostos oriundos das raízes de alface foram capazes de induzir o desenvolvimento de hifas. Embora não tenham sido determinadas suas naturezas químicas, não se exclui a possibilidade de que se trate de compostos fenólicos, uma vez que a massa molecular dos exudados por eles isolados foi menor que $500 \mathrm{Da}$.

Não se sabe exatamente como ocorre a infecção das raízes por FMAs. Aparentemente, deve ocorrer penetração por ação enzimática e pressão mecânica. (Bonfante, 1994; Bonfante-Fasolo, 1984).

De modo bem resumido, pode se dizer que após o fungo estabelecer contato com a raiz da planta, uma seqüência de eventos direcionados pelos genomas tanto da planta 
como do fungo, e modulados pelas condições do ambiente, irão determinar o sucesso ou falha da penetração e da colonização intrarradicular (Lambais, 1996; Siqueira, 1986).

Após a penetração, o fungo coloniza o tecido cortical inter e intracelularmente, limitando-se aos tecidos externos à endoderme, e diferencia-se em arbúsculos no interior de algumas células do córtex (Bonfante-Fasolo, 1992). O processo de colonização é contínuo, acompanhando o crescimento da raiz (Bonfante-Fasolo, 1984).

Todos os fatores que influenciam o desenvolvimento da planta também têm alguma influência sobre o estabelecimento e eficiência da associação micorrízica, direta ou indiretamente (Fitter \& Merrywether, 1992). No caso do P, já foi proposto que o seu baixo nível na planta, ao aumentar a permeabilidade das membranas, permite uma maior exsudação de compostos orgânicos, os quais teriam efeito positivo sobre o estabelecimento da associação (Graham et al., 1981; Schubert \& Hayman, 1986; Schwab et al., 1983; 1991).

Os conhecimentos mais recentes sobre a fisiologia das MAs sugerem que o seu desenvolvimento envolve um sistema complexo de regulação gênica e pode estar relacionado com o sistema de defesa vegetal (Gianinazzi-Pearson, 1996; GianinazziPearson et al., 1995). Evidências indicam que altas concentrações de $\mathrm{P}$ na planta induzem respostas de defesa, o que pode estar associado com o reduzido nível de colonização nessas condições (Lambais \& Mehdy, 1993; 1995). Apesar da regulação de genes de defesa, as chamadas reações de hipersensibilidade (aumento da concentração de fitoalexinas e morte celular), aparentemente não ocorrem em MAs (Gianinazzi-Pearson, 1996; Gianinazzi-Pearson et al., 1996). Esses dados sugerem que MAs possuem mecanismos eficientes de controle do sistema de defesa vegetal.

A seguir, serão abordados alguns pontos dos chamados mecanismos de defesa vegetal mais relacionados com o processo de formação das MA 


\subsubsection{Reações de defesa vegetal em micorrizas arbusculares}

A invasão do tecido vegetal por microorganismos patogênicos é controlada por um conjunto de características inerentes à planta ou por alterações bioquímicas durante o processo de infecção (Pascholati \& Leite, 1995). Convencionalmente, esses mecanismos são classificados em constitutivos (ou pré-formados) e induzidos (ou ativos). Quanto à sua natureza, são diferenciados em físicos (ou estruturais) e bioquímicos (Agrios, 1988; Pascholati \& Leite, 1995). Cada uma dessas barreiras resulta da expressão do genótipo da planta e deve ser suplantada pelo microorganismo invasor (Pascholati, 1995).

A expressão das chamadas reações de defesas ocorre graças a eficientes mecanismos de percepção de estímulos, através da atuação de quimiorreceptores específicos, localizados na membrana citoplasmática vegetal. (Dixon et al., 1994; Pascholati \& Leite, 1995). Esses receptores são ativados por moléculas (elicitores) originários do microrganismo invasor ou do próprio tecido hospedeiro danificado durante o processo de infecção (Dixon et al., 1994; Leite et al., 1997). Na transdução dos sinais moleculares primários pode ocorrer aumento aumento do influxo de $\mathrm{Ca}^{+2}$, fosforilação e/ou desfosforilação de proteínas, geração de espécies ativas de oxigênio (EAOs) e síntese de AS, dentre outras respostas (Enyedi et al., 1992).

Durante o processo de invasão do tecido vegetal por fungos patogênicos, se observa produção e acúmulo de compostos com atuação fungitóxica e/ou fungistática denominados fitoalexinas (Salunkhe \& Sharma, 1991). As fitoalexinas podem atuar na contenção de fungos patogênicos na região ao redor do sítio de infecção (Pascholati \& Leite,1995; Stangarlin, 1995). A síntese de tais compostos ocorre pelas vias do ácido chiquímico e ácido cinâmico (fenilpropanóides) (Ebel, 1986; Nicholson \& Hammerschmidt,1992). As células ao redor do tecido infectado sofrem apoptose e com sua degeneração ocorre liberação de fitoalexinas (Milosevic \& Slusarenko, 1996). Quando ocorre um injúria do tecido vegetal observa-se o desencadeamento de reações localizadas, envolvendo EAOs, as quais podem atuam na polimerização oxidativa de fenilpropanóis (síntese de ligninas) e na sinalização intra e intercelular (Chen et al., 
1993; D’auzac, 1996; Strack \& Mock, 1993). Além disso, observa-se também o aumento das atividades de hidrolases que podem atuar sobre componentes da parede celular do fungo. Dentre elas, quitinases (E.C. 3.2.1.14) e $\beta$-1,3-glicanases (E.C. 3.2.1. 39), são as mais observadas nos estudos de interação planta-patógeno (Guzzo \& Martins, 1996; Neuhaus et al., 1991). No entanto, os elevados níveis de atividade dessas enzimas nem sempre estão relacionados com aumento da resistência (Ji \& Kúc, 1996; 1997).

Tem sido observada em MAs, indução de reações de defesa diferenciadas com o genótipo da planta e fungo. Harrison \& Dixon, (1993) observaram aumento da fitoalexina medicarpina e dos transcritos das enzimas envolvidas na síntese de flavonóides (FAAL, chalcona sintetase) na fase inicial da colonização (7 e 13 dias após a inoculação) das raízes de Medicago truncatula por Glomus vesiforme. Na fase mais avançada (40 dias após a inoculação), foi observado decréscimo significativo da concentração de medicarpina em plantas colonizadas em relação ao controle (plantas não inoculadas). No entanto, tal redução não foi observada na interação incompatível do mesmo fungo micorrízico com uma linhagem não susceptível à micorrização (mic") de Medicago. sativa. Volpin et al (1994) observaram que a elevação dos niveis de atividade de chalcona isomerase ( $\mathrm{CHI}$ ) e quitinases em raizes de $M$. sativa antecederam a fase de colonização por $G$. intraradices, enquanto a de fenilalanina amônia liase (FAAL) aumenta com a fase inicial do processo de colonização. Lambais \& Mehdy (1996) observaram que o padrão de expressão das atividades de CHI, quitinases e $\beta$-1,3glicanases em raízes de soja foi diferente para isolados de $G$. intraradices com diferentes infectividades.

O aumento das atividades de enzimas relacionadas com as reações de defesa vegetal durante a fase inicial da colonização intrarradicular por FMAs é acompanhado da observação de seus transcritos (Lambais \& Mehdy, 1993; 1998; Volpin et al., 1994), indicando ativação dos mecanismos de defesa. No entanto, não são observadas reações de hipersensibilidade, comuns durante o processo de infecção por fungos patogênicos. 


\subsubsection{Atividades de Quitinases e $\beta$-1,3-glicanases em micorrizas arbusculares}

Quitinases (E.C. 3.2.1.14), são enzimas que catalisam a hidrólise das ligações $\beta$ 1,4 de polímeros de $N$-acetil glicosamina (Boller \& Vögeli, 1984). Elas estão relacionadas tanto com a formação quanto com a degradação da parede celular dos fungos, que contêm quitina em sua paredes celulares (Bolawa, 1993; Griffin,1994).

As atividades quitinases em plantas podem ser induzidas pela infecção por fungos (Neuhaus et al., 1991), bactérias (Guzzo \& Martins, 1996) e vírus (Bol et al., 1990). Podem ser induzidas também por etileno (Mauch \& Staehelin, 1989), AS (Chen et al., 1993), ozônio (Ernst et al., 1992), ou ainda, por moléculas elicitoras oriundas da parede celular de fungos. Normalmente, isoformas básicas são vacuolares e as ácidas são extracelulares. Essas isoformas podem apresentar expressão diferencial em interação planta microrganismos (Awade et al., 1989; Dassi et al, 1996; Dumas-Gaudot et al, 1996 Boller \& Vögeli, 1984).

$\beta$-1-glicanases também são enzimas hidrolíticas produzidas tanto por fungos (Bol et al., 1990; Griffin, 1994) como por plantas (Cassab \& Varner, 1988). Nas plantas, podem localizar-se na parede celular (Cassab \& Varner, 1988; Mauch \& Staehelin, 1989) ou nos vacúolos (Kunze et al., 1998). Essas hidrolases estão envolvidas tanto no processo de formação e elongação da parede celular vegetal (Helleboid et al., 1998), quanto nas reações de defesa da planta contra a infecção por patógenos. Podem ser induzidas por etileno (Mauch \& Staehelin, 1989), AS e moléculas elicitoras (Bowles, 1990).

Em folhas de feijão, as atividades de $\beta$-1-glicanases é co-regulada com a de quitinases (Vögeli et al., 1988).

De modo geral se observa indução transiente das atividades de quitinases na fase inicial do processo de colonização de raízes de plantas hospedeiras por FMAs, seguida de supressão (David et al., 1998; Lambais \& Mehdy, 1993, 1996; Volpin et al., 1994). No entanto, as isoformas induzidas em simbioses mutualísticas podem ser diferentes das 
induzidas em plantas infectadas por patógenos (Dassi et al., 1996; Dumas-Gaudot et al., 1996; Pozo et al, 1996).

Pittock et al., (1997) constataram a expressão de um gene codificando uma isoforma básica de quitinase nas extremidades de crescimento das raízes e em pontos injuriados. Além disso, o gene teve expressão transiente em raízes inoculadas com linhagens compatíveis de Rhizobium. O fato de não terem observado expressão do gene em raízes inoculadas com substâncias indutoras da formação de nódulos (fatores Nod) foi considerado pelos autores como um indicativo de que a expressão desse gene está também intimamente relacionado com as reações de defesa e pode afetar a formação de nódulos.

Lambais \& Mehdy (1996) visando estabelecerem um paradigma para novos estudos sobre os mecanismos de controle da expressão de quitinases e $\beta$-1,3-glicanases em MAs, propuseram um modelo hipotético para explicar as possíveis funções e mecanismos de regulação das atividades de quitinases e $\beta$-1,3-glicanases. Nesse modelo, uma molécula sinal, gerada em resposta à infecção induziria reações de defesa, tais como atividades de endoquitinases ácidas e $\beta$-1,3-glicanases ou de outras enzimas relacionadas com as respostas de defesa, de acordo com nível de $\mathrm{P}$ na planta. Alternativamente, diferentes moléculas sinais geradas em condições de baixo e alto $\mathrm{P}$, poderiam suprimir ou induzir as atividades de quitinases e $\beta$-1,3-glicanases. A supressão de respostas de defesa, poderia ser decorrente de alterações no balanço hormonal. Outra possibilidade seria a atuação de moléculas supressoras geradas durante o processo de colonização.

Nas reações de defesa vegetal contra patógenos, o ácido salicílico atua como molécula sinal para a indução dessas reações. No entanto, não se sabe qual a sua participação durante a formação das micorrizas arbusculares.

A seguir serão abordadas algumas informações sobre a participação do ácido salicílico nas reações de defesa vegetal. 


\subsection{O envolvimento do ácido salicílico nas reações de defesa vegetal}

O ácido orto-hidroxibenzóico, mais conhecido como ácido salicílico (AS) foi identificado como sendo uma molécula sinal para indução da chamada resistência sistêmica adquirida (RSA) em fumo infectado por vírus do mosaico do fumo (TMV) (Gaffney et al., 1993; Yalpani et al., 1991). Devido à sua atuação generalizada e em baixas concentração, foi sugerido tratar-se de mais um hormônio vegetal (Raskin, 1992). Shulaev et al. (1997) mostraram evidências de que a ação generalizada do AS pode ser devido a sua transformação em metil salicilato, um composto volátil em temperatura ambiente capaz de induzir reações de defesa da planta em concentrações nanomolares. $O$ AS, quando aplicado sobre a parte aérea, é responsável pela indução da síntese de proteínas relacionadas à patogênese (proteínas-RP), inclusive quitinases e $\beta$-1,3glicanases (Chen et al., 1993).

Presume-se que a síntese do AS seja a partir do ácido cinâmico, através de duas possíveis vias. A primeira por uma $\beta$-oxidação e a segunda por uma ortohidroxilação. A primeira parece ser mais ativa em plantas não-infectadas, enquanto que a segunda parece mais relacionada com indução por patógenos (Raskin, 1992, 195).

Embora seja de ampla aceitação a indução da síntese de proteínas-RP pelo AS (Gaffney et al., 1993; Ohashi \& Matsuoka, 1987; Yalpani et al., 1991), ainda são controvertidos os resultados sobre o mecanismo de indução. É possível que a indução das atividades de quitinases por AS ocorra através da síntese de etileno (Bowles, 1990).

Rao et al., (1997) investigaram o envolvimento do AS na indução das reações de defesa e o seu relacionamento com o aumento da concentração de $\mathrm{H}_{2} \mathrm{O}_{2}$ nas plantas. Eles observaram a redução das atividades de catalase e ascorbato peroxidase, com conseqüente sintomas de fitotoxicidade característico de resposta de hipersensibilidade. Também propuseram um modelo hipotético mostrando a interdependência entre o AS e $\mathrm{H}_{2} \mathrm{O}_{2}$ no estabelecimento da resistência sistêmica. Segundo esse modelo, o aumento dos níveis de AS no tecido vegetal resulta em maiores concentrações de EAOs, as quais alteram o estado de oxidação de componentes da parede celular e ativam vários genes de 
defesa. No entanto, a ação do AS na indução de respostas de hipersensbilidade e morte da célula pode não ser conseqüência da inibição de catalases (Tenhaken \& Rübel, 1997). Srivastava \& Dwivedi (1998) verificaram que o AS inibe as atividades de catalases e peroxidases e induz o aumento da concentração de glutationa. Embora se observe aumento de EAOs pela aplicação de AS, não se sabe se isso ocorre por diminuição das atividades responsáveis pela inativação das EAOs geradas ou por uma indução da geração das EAOs.

O efeito do AS no desenvolvimento das MAs não é conhecido. No entanto, se o AS está envolvido na indução das atividades de quitinases e $\beta$-1,3-glicanases, e se essas enzimas estão envolvidas no controle do crescimento fúngico intraradicular, é provável que o AS iniba a formação de MAs, similarmente à inibição que se observa em plantas com altas concentrações de $P$. 


\section{MATERIAL E MÉTODOS}

\subsection{Material biológico}

Foram utilizados esporos dos fungos Glomus intraradices Schenck \& Smith e G. clarum Nicolson \& Shenck, obtidos de vasos de multiplicação do Departamento de Ciência do Solo ESALQ. A planta utilizada foi o feijoeiro (Phaseolus vulgaris L var. Carioca 80-SH), cujas sementes foram cedidas pela Seção de Leguminosas do Instituto Agronômico de Campinas.

\subsection{Montagem, condições de cultivo e procedimentos de colheita}

\subsubsection{Preparação do substrato, plantio e inoculação}

Como substrato de cultivo foi utilizada uma mistura, na proporção $(1: 3 \mathrm{v} / \mathrm{v})$ de vermiculita expandida textura fina Plantmax ${ }^{\circledR}$ Eucatex $^{\mathrm{TM}}$ com areia passada em peneira ( $2 \mathrm{~mm}$ ). Ambas foram lavadas em água corrente e depois postas para secar ao ar. A proporção areia:vermiculita foi 3:1 (v/v). A mistura foi autoclavada por dois ciclos de 2 horas a $120^{\circ} \mathrm{C}$ e $1 \mathrm{~atm}$. Em seguida, retirou-se uma amostra para análise química.

Fez-se uma adubação, 2 dias antes do plantio, com as seguintes quantidades (mg L $\mathrm{L}^{-1}$ de substrato) de nutrientes e respectivas fontes: 20 de $\mathrm{N}\left(\mathrm{NH}_{4} \mathrm{NO}_{3}\right), 100$ de $\mathrm{K}$ $(\mathrm{KCl}), 40$ de $\mathrm{Ca}\left(\mathrm{CaCl}_{2}\right), 20 \mathrm{de} \mathrm{Mg}\left(\mathrm{MgSO}_{4} \cdot 7 \mathrm{H}_{2} \mathrm{O}\right)$. Além disso, usou-se 0,5 $\mathrm{mL}$ de solução de micronutrientes (sem $\mathrm{Mn}$ ) e $0,5 \mathrm{~mL}$ de Fe-EDTA, ambas na formulação padrão da solução de Hoagland, para cada vaso. O P foi aplicado na concentração de 20, para as parcelas de baixo $\mathrm{P}$, ou $150 \mathrm{mg} \mathrm{L} \mathrm{L}^{-1}$ para as de alto, usando-se $\mathrm{KH}_{2} \mathrm{PO}_{4}$. 
Ao longo do cultivo, foram feitas aplicações de $20 \mathrm{mg}$ de $\mathrm{N} \mathrm{L}^{-1}$ de substrato, na forma de solução. Na primeira aplicação (20 dias após o plantio) e na terceira (42 dias após o plantio) usou-se a mesma fonte usada no plantio. Na segunda (33 dias após o plantio) usou-se $\mathrm{Ca}\left(\mathrm{NO}_{3}\right)_{2}$.

Como fontes de inóculo, utilizou-se $10 \mathrm{~mL}$ de uma suspensão com 2000 esporos de um dos fungos testados, para cada vaso de cultivo. Como controle negativo, nas parcelas não-inoculadas, aplicou-se $10 \mathrm{~mL}$ do filtrado da suspensão de esporos. A inoculação foi feita sobre a radícula das sementes germinadas antes de serem cobertas por substrato.

Obteve-se as plantas a partir de sementes pré-germinadas. Sendo que, primeiramente as sementes foram desinfestadas por imersão em solução de hipoclorito comercial com concentração aproximada de 2,0 a $2,5 \%$, durante 4 min, seguida de lavagem sob fluxo de $\mathrm{H}_{2} \mathrm{O}$ ddi por 5 min e permanência em $\mathrm{H}_{2} \mathrm{O}$ ddi durante 30 min, com trocas a cada $10 \mathrm{~min}$. Depois disso, foram colocadas em placas-de-Petri estéreis com algodão umedecido com $\mathrm{H}_{2} \mathrm{O}$ ddi estéril, e deixadas a $28{ }^{\circ} \mathrm{C}$ no escuro, por aproximadamente $48 \mathrm{~h}$, afim de que germinassem. Depois de germinadas, plantou-se uma em cada vaso, selecionado-se as mais homogêneas.

\subsubsection{Condução, condições de cultivo e colheita}

A execução desse experimento deu-se no período de 07/08/97 a 16/10/97. Segundo o Departamento de Física e Agrometereologia da ESALQ, a radiação e a insolação média registradas durante o período experimental foram: $371,34 \mathrm{cal} / \mathrm{cm}^{2} / \mathrm{dia}$ e $3,96 \mathrm{~h} / \mathrm{d}$, respectivamente, conforme dados coletados na estação meteorológica localizada na área da escola $\left(22^{0} 42^{\prime} 30^{\prime \prime} \mathrm{S}, 47^{0} 38^{\prime} \mathrm{W}, 546 \mathrm{~m}\right)$, próxima ao local do experimento. No interior da casa de vegetação, a média das temperaturas máximas foi $34,5 \pm 4,4^{\circ} \mathrm{C}$ e das mínimas $18 \pm 2,5^{\circ} \mathrm{C}$ (figura 1 - Apêndice 3 ). 
O AS foi aplicado na forma de solução (5,0 mL por vaso) com auxílio de um dispensador, sobre o substrato de cultivo, a cada dois dias, a partir de 2 semanas após o plantio (SAP). Uma semana depois, a aplicação foi interrompida, retomada sete dias depois, e continuou sendo feita de 2 em 2 dias nas plantas remanescentes, até a última colheita. AS soluções de AS foram preparadas a cada 4 dias, por diluição de uma solução estoque (10x). A solução estoque foi preparada pela adição de $2 \mathrm{~g}$ de AS (art. 631 Merck (B) em $900 \mathrm{~mL}$ de $\mathrm{H}_{2} \mathrm{O}$ ddi esterilizada, ajustando-se o $\mathrm{pH}$ para 7,0 $\pm 0,5 \mathrm{com}$ $\mathrm{NaOH}$ e em seguida, completando-se o volume com $\mathrm{H}_{2} \mathrm{O}$ ddi esterilizada para $1 \mathrm{~L}$.

A dose e o intervalo de aplicação do AS foram definidos com base em ensaios preliminares que objetivaram determinar a duração do efeito sobre a atividade de quitinases e $\beta-1,3$ glicanases devida a aplicação da dose de AS definida como a mais efetiva sobre a atividade dessas enzimas e sem efeito tóxico para o feijoeiro (Phaseolus vulgaris $\mathrm{L}$ var. Safira)

Aos 45 dias após o plantio, fez-se uma pulverização de acaricida (Omitß) $720 \mathrm{CE}, 2 \mathrm{~mL} \mathrm{~L}^{-1}$ ) e 2 dias depois, outra usando-se Dicofol ${ }^{\circledR}$ na dosagem de $1 \mathrm{~mL}$ do produto comercial por $\mathrm{L}$ de água. Dois dias após a terceira colheita (58 dias após o plantio) fez-se outro controle de ácaros aplicando-se Vertimec ${ }^{\circledR} 18 \mathrm{CE}$ na dosagem de $0,5 \mathrm{~mL} \mathrm{~L}^{-1}$.

As plantas foram colhidas 4, 6, 8 e $10 \mathrm{SAP}$ separando-se o sistema radicular (SR) da parte aérea (PA). O SR de todas as plantas foram lavados e enxugados. Em seguida, retirou-se uma porção do terço médio do SR para determinação do nível de colonização micorrízica. Uma outra porção do SR, imediatamente abaixo, foi retirada para se estimar matéria seca do SR, seca a $65^{\circ} \mathrm{C}$. Estimou-se os valores por extrapolação com base na umidade da porção retirada e da matéria fresca total do SR. A parte restante foi congelada em nitrogênio líquido e armazenada a $-80{ }^{\circ} \mathrm{C}$ até o processamento para análises bioquímicas. A massa seca da parte aérea foi determinada após secagem em estufa a $65^{\circ} \mathrm{C}$ até massa constante. 


\subsection{Avaliação do nível de colonização micorízica}

Após a colheita, as amostras das raizes foram preservadas em solução de AFA (5\% Ácido acético glacial, 3,7\% Formaldeído, $25 \%$ etanol, em água).

A coloração das raízes foi feita com base no procedimento descrito por Phillips $\&$ Hyman (1970). As raizes foram tratadas em solução de KOH $10 \%$ em banho-maria a $90^{\circ} \mathrm{C}$ por 50 min, lavadas com água corrente, clarificadas com $\mathrm{HCl} 1 \%$ e coloridas com uma solução de azul-de-tripano em lactoglicerol.

A determinação da porcentagem de colonização das raízes pelos fungos micorrízicos foi feita por observação em microscópio estereoscópio, em placa reticulada (Giovannetti \& Mosse, 1980).

\subsection{Extração e quantificação de proteínas}

Foi feita baseando-se no procedimento descrito por Lambais \& Mehdy (1993). Subamostras do SR ( $3 \mathrm{~g}$ ) foram maceradas em nitrogênio líquido, homogeneizadas em 9 $\mathrm{mL}$ de solução tampão (100 mM de Na-citrato pH 5,0; $5 \mathrm{mM}$ de EDTA pH 8,0;1 mM de PMSF (Fluoreto de metanosufonil); $1 \mu \mathrm{M}$ de $\beta$-mercaptoetanol). A homogeneização foi feita em um "mixer" modelo MA 102 Tecnal $^{\circledR}$ em média rotação por $2 \mathrm{~min}$. Em seguida, as amostras foram centrifugadas a $20000 \mathrm{~g}$, por $20 \mathrm{~min}$, a $4{ }^{\circ} \mathrm{C}$ em uma centrífuga Sorvall $®$ Du Pont ${ }^{\mathrm{TM}}$ modelo RC5C. O sobrenadante recuperado foi congelado e mantido a $-20{ }^{\circ} \mathrm{C}$ até o momento de utilização.

A quantificação do conteúdo protéico foi feita pelo método de Bradford (1976), utilizando-se o procedimento em microplacas do Kit comercial BioRad ${ }^{\mathrm{TM}}$ e albumina de soro bovino (ASB) como padrão. Para isso diluiu-se $300 \mu \mathrm{l}$ do extrato bruto em $300 \mu \mathrm{l}$ de tampão Na-citrato $100 \mathrm{mM}$ pH 5,3. Distribuiu-se $200 \mu \mathrm{l}$ de cada amostra diluída em microplacas 96 WELL ELISA Corning ${ }^{\circledR}$, adicionou-se $50 \mu$ do reagente de Bradford concentrado e fez-se a determinação da absobância a $595 \mathrm{~nm}\left(\mathrm{~A}_{595}\right) \mathrm{em}$ 
espectrofotômetro de microplacas modelo $550 \mathrm{BioRad}^{\mathrm{TM}}$. Os resultados foram expressos em $\mu \mathrm{g}$ equivalente de $\mathrm{ASB}$ por $\mathrm{mL}$ de extrato ( $\mu \mathrm{g}$ proteína $\mathrm{mL}^{-1}$ ). As determinações foram feitas em triplicatas.

\subsection{Determinação da atividade de quitinases}

As atividades de quitinases (EC 3.2.1.14) foram determinadas colorimetricamente pela liberação de fragmentos solúveis de quitina marcada com remazol violeta brilhante (CM-chitin RBV, LOWE bioquímica, Munique, Alemanha), conforme descrito por Wirth \& Wolf (1990), com algumas modificações.

O conteúdo protéico de cada amostra foi ajustado para concentração de $4,8 \pm 0,5 \mu \mathrm{g} \mathrm{mL} \mathrm{m}^{-1}$, completando-se um volume final de $950 \mu \mathrm{L}$ com Na-citrato $0,1 \mathrm{M} \mathrm{pH}$ 5,3. Essa concentração corresponde a um ponto escolhido da faixa linear de atividade preliminarmente determinada. A cada amostra ajustada, adicionou-se $150 \mu \mathrm{L}$ do substrato (CM-Chitin-RBV $2 \mathrm{mg} \mathrm{mL}^{-1}$ ). Em seguida incubou-se por $30 \mathrm{~min}$ em 'banhomaria' a $37^{\circ} \mathrm{C}$. Interrompeu-se a reação colocando-se os tubos de reação no gelo. Para precipitar o substrato não degradado, adicionou-se $150 \mu \mathrm{l}$ de $\mathrm{HCl} 1 \mathrm{~N}$ e centrifugou-se por $5 \mathrm{~min}$ a $5000 \mathrm{~g}$ a $4^{\circ} \mathrm{C}$. A centrifugação foi feita em uma mini-centrifuga modelo MSE Sanyo $\left(\mathbb{R}\right.$ previamente colocada em câmara fria $\left(4^{\circ} \mathrm{C}\right) \mathrm{A}$ absobância do sobrenadante foi determinada a 550nm, tomando-se o tampão de extração misturado ao substrato como prova em branco. Os resultados foram expressos em unidades de absobância por minuto e por mg Equivalentes de BSA (UA $\mathrm{U}_{50} \mathrm{~min}^{-1} \mathrm{mg}^{-1} \mathrm{Eq}$. BSA). Foram feitas 4 réplicas de cada amostra, totalizando 16 leituras para cada tratamento, divididas em duas vezes. Considerou-se as médias das réplicas como o resultado das repetições de cada tratamento. Esses valores foram usados para as análises estatísticas. 


\subsection{Determinação das atividades de $\beta-1,3$-glicanases}

As atividades de $\beta$-1,3-glicanases, foram determinadas pela degradação de $\beta$ 1,3-glicana marcada com remazol azul brilhante (CM-Curdlan-RBB, LOEWE Biochemica, Munique, Alemanha).

As amostras tiveram seus conteúdos protéicos ajustados para $40 \pm 5 \mu \mathrm{g}$ Eq. BSA $\mathrm{mL}^{-1}$, pela diluição em tampão Na-citrato $0,1 \mathrm{M} \mathrm{pH} 5,3$, para um volume final de $950 \mu \mathrm{L}$. A cada amostra diluída adicionou-se $150 \mu \mathrm{L}$ do substrato marcado (CM-Curdlan-RBB, 4 $\mathrm{mg} \mathrm{mL} \mathrm{m}^{-1}$ ) e incubou-se durante $1 \mathrm{~h} \mathrm{em}$ "banho-maria" a $37^{\circ} \mathrm{C}$. Interrompeu-se a reação colocando-se as amostra em gelo e adicionando-se $150 \mu \mathrm{L}$ de $\mathrm{HCl} 2 \mathrm{~N}$. Em seguida, determinou-se a Absobância a $600 \mathrm{~nm}\left(\mathrm{~A}_{600}\right)$ do sobrenadante obtido pela centrifugação das amostras a $9000 \mathrm{~g}$ por $5 \mathrm{~min}$. Os valores de atividade foram expressos em Unidade de Absobância a $600 \mathrm{~nm}$ por $\mathrm{mg}$ de proteínas por hora $\left(\mathrm{UA}_{600} \mathrm{mg}^{-1} \mathrm{~h}^{-1}\right)$. As reações foram feitas em séries compostas de 3 réplicas de 4 amostras por vez. Considerou-se as médias das réplicas como o resultado das repetições de cada tratamento. Esses valores sofreram o mesmo processo que os da variável anterior para análise estatística.

\subsection{Delineamento, unidade experimental e análise estatística}

As unidades experimentais consistiram de plantas de feijoeiro, em vasos contendo $1 \mathrm{~L}$ de substrato, cultivadas sob condições de casa-de-vegetação.

A análise foi feita seguindo-se o modelo estatístico para um conjunto de experimentos em delineamento inteiramente ao acaso. Cada um desses experimentos foi organizado em esquema fatorial. Com 5 repetições para a variável MSPA e 4 para as variáveis bioqúimicas. Os fatores de tratamento e respectivos niveis foram: Inoculação (Sem fungo, G. intraradices, G. clarum); Níveis de P (baixo e alto, 32 e $162 \mathrm{mg} \mathrm{L}^{-1}$ de substrato, respectivamente) ,e; AS (sem aplicação e com 7,24 $\mu \mathrm{mol} \mathrm{L} \mathrm{L}^{-1}$ de substrato). Para adotar tal procedimento, considerou-se o fator doses de AS como uma condição fixa que foi avaliada nas diferentes épocas de colheita. 
Para diferenciação das médias aplicou-se o teste " $t$ " de Student $(p<0,05)$. 


\section{RESULTADOS E DISCUSSÃO}

\subsection{Efeito sobre a produção de biomassa vegetal}

A concentração de AS e sua freqüência de aplicação foram definidas em feijoeiro variedade Safira, em condições de alto $\mathrm{P}$, de modo a não ocorrer fitotoxidez (dados não apresentados). No entanto, na variedade Carioca $80-\mathrm{SH}$, constatou-se efeito inibitório significativo (teste $t, p<0,05$ ) do AS sobre o acúmulo de biomassa vegetal (MSPA), tanto nas plantas não-inoculadas quanto nas inoculadas, colhidas com 4, 6 e 10 SAP. Com 8 SAP, houve efeito de interação do fator AS, distintamente com níveis de $\mathrm{P}$ e inoculação (Tabela 2 - Apêndice 2).

A aplicação de AS não afetou significativamente a produção de biomassa aérea (teste $\mathrm{t}, \mathrm{p}<0,05$ ) das plantas inoculadas com G. clarum, independentemente da dose de $\mathrm{P}$. De uma maneira geral, a inoculação de $G$. clarum ou $G$. intraradices não afetou significativamente o crescimento das plantas, comparado com os tratamentos nãoinoculados, dentro de cada um dos níveis de AS, em condições de baixo ou alto $\mathrm{P}$, com exceção da inoculação com G. clarum, em plantas que receberam AS, a qual estimulou o crescimento da parte aérea, em relação aos controles não-inoculados (Figura 1). Aparentemente, a inoculação de fungos micorrízicos arbusculares eficientes em colonizar o sistema radicular pode aliviar os efeitos tóxicos do AS sobre o feijoeiro. Como o AS está envolvido na geração de espécies ativas de oxigênio em tecidos vegetais (Rao et al., 1997), é possível que algumas MAs, dependendo da interação fungo-planta, possuam mecanismos anti-oxidativos mais eficientes do que em raízes não-micorrizadas, aumentando assim sua tolerância ao AS e outros estresses ambientais. 


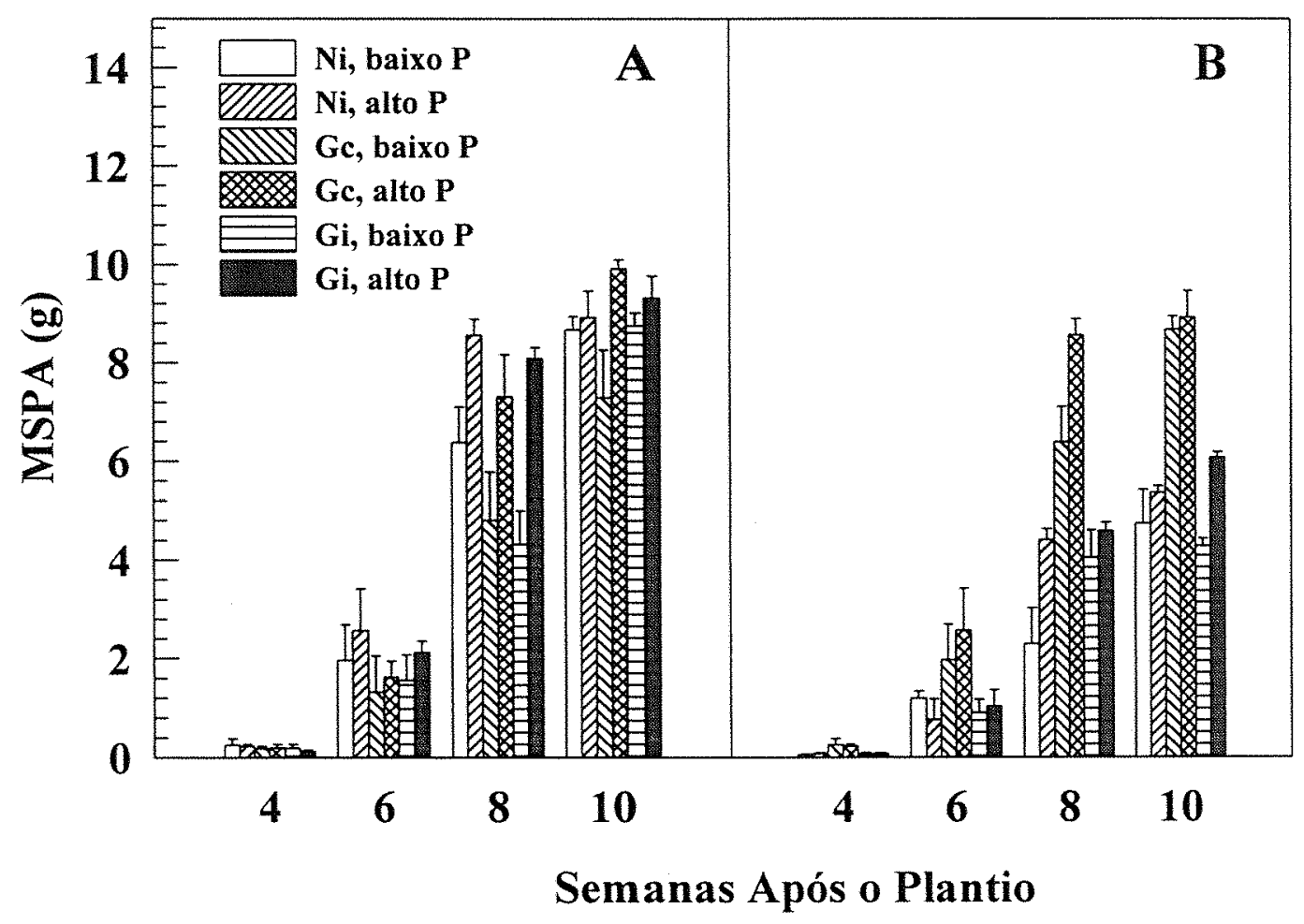

Figura 1. Matéria seca da parte aérea (MSPA) de feijoeiros não-inoculados ou inoculados com Glomus clarum (Gc) ou Glomus intraradices (Gi), em condições de baixo (32 $\mathrm{mg} \mathrm{L}^{-1}$ de substrato) ou alto $\mathrm{P}$ (162 $\mathrm{mg} \mathrm{L}^{-1}$ de substrato). A. Sem aplicação de ácido salicílico. B. Com aplicação de ácido salicílico $(7,24 \mu \mathrm{mol}$ a cada 2 dias, a partir de duas semanas após o plantio). Os dados são médias de 4 repetições \pm desvio padrão da média. 


\subsection{Efeito sobre o nível de colonização micorrízica}

Não foi constatado nenhum sinal de colonização nas raízes de qualquer uma das unidades experimentais não-inoculadas (Ni). Nas demais parcelas, a colonização foi variável de acordo com os níveis dos fatores de tratamento. $\mathrm{O}$ resultado da análise de variância acusou efeito de interação entre os três fatores na colheita feita com 8 SAP. O efeito de interação tripla também foi observado nas amostras colhidas $10 \mathrm{SAP}$, mas ao nível de 5,1\% (Tabela 3-Apêndice 2).

Nas raízes inoculadas com $G$. clarum ou $G$. intraradices, os maiores níveis de colonização intrarradicular foram observados $10 \mathrm{SAP}$ (Figura 2). Tanto na presença quanto na ausência de AS, G. clarum apresentou maior eficiência em colonizar o tecido cortical das raízes do feijoeiro (infectividade) do que $G$. intraradices, em todas as épocas de amostragem (teste $\mathrm{t}, \mathrm{p}<0,05)$ Em feijoeiro, aparentemente, a infectividade de $G$. intraradices está relacionada com a variedade da planta cultivada. $\mathrm{Na}$ variedade Tendergreen, taxas de colonização intrarradicular mais elevadas do que as obtidas nesses experimentos já foram observadas, em condições de cultivo semelhantes (Lambais \& Mehdy, 1993). Na variedade Safira, no entanto, as taxas de colonização por $G$. intraradices foram inferiores às observadas na variedade Carioca 80-SH (dados não apresentados). Esses dados demonstram que, embora os fungos micorrízicos sejam considerados simbiontes não-específicos, o nível de colonização intrarradicular depende da interação dos genótipos da planta e do fungo (Mosse, 1973; Fitter \& Merryweather, 1992; Koide \& Schreiner, 1992; Lambais \& Mehdy, 1996).

A colonização intrarradicular foi inibida pelo aumento da concentração de $\mathrm{P}$ no substrato, independente da aplicação de AS (Figura 2). Na ausência de AS, os níveis de colonização por $G$. clarum e $G$. intraradices em condições de alto P, $10 \mathrm{SAP}$, foram $63 \%$ e $62 \%$ menores, respectivamente, do que em condições de baixo P (Figura $2 \mathrm{~A}$ ). Na presença de AS, os níveis de colonização por $G$. clarum, em condições de alto $\mathrm{P}$, foram $90 \%$ menores do que em condições de baixo $\mathrm{P}$, enquanto que a colonização por $G$. intraradices foi totalmente inibida (Figura 2B). O efeito inibitório do $\mathrm{P}$ sobre a 


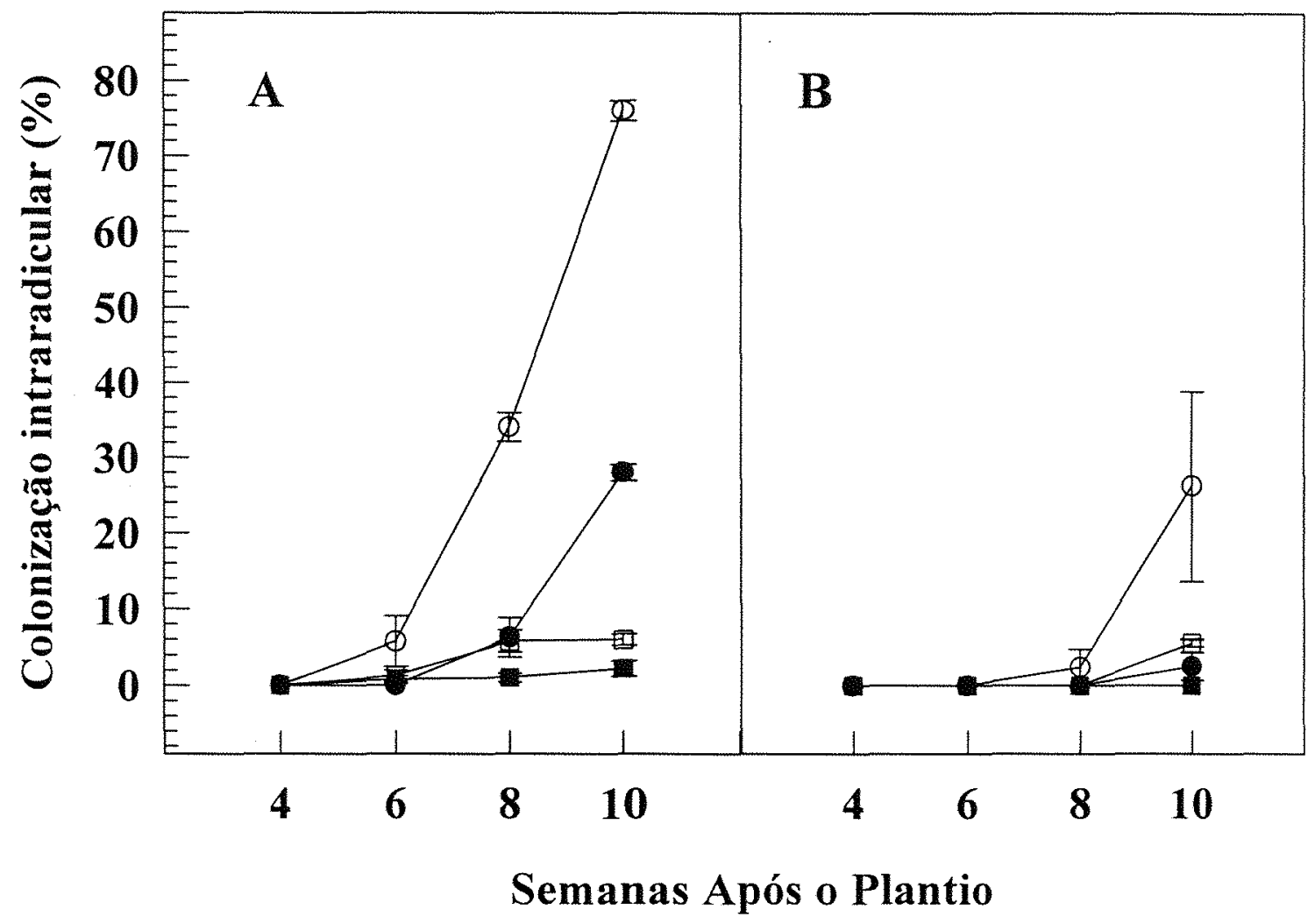

Figura 2. Porcentagem de colonização de raízes de feijoeiro inoculadas com Glomus clarum $(\mathrm{O}, \mathbf{0})$ ou Glomus intraradices $(\square, \mathbf{E})$, em condições de baixo (32 mg L $\mathrm{L}^{-1}$ de substrato; O, $\square$ ) ou alto P (162 $\mathrm{mg} \mathrm{L}^{-1}$ de substrato; $\mathbf{\square}$ ). A. Sem aplicação de ácido salicílico. B. Com aplicação de ácido salicílico $(7,24$ $\mu \mathrm{mol}$ a cada 2 dias, a partir de duas semanas após o plantio). Os dados são médias de 4 repetições \pm desvio padrão da média. 
colonização das raízes por fungos micorrízicos arbusculares é conhecido de longa data (Abbott et al., 1984). No entanto, o mecanismo bioquímico que determina o menor crescimento fúngico intrarradicular não é conhecido. Tem sido sugerido que a ativação do sistema de defesa vegetal em condições de alto $\mathrm{P}$ estaria envolvida no controle do desenvolvimento de MAs (Lambais \& Mehdy, 1995). Em altos niveis de P, a supressão do sistema de defesa, observada em raízes micorrizadas sob baixos níveis de $\mathrm{P}$, é atenuada. Adicionalmente, em raizes de feijão Tendergreen colonizadas por $G$. intraradices, isoformas específicas de quitinases foram induzidas em células contendo arbúsculos e/ou sua proximidade sob condições de alto P (Lambais \& Mehdy, 1998), o que poderia contribuir para limitar a colonização do tecido cortical nessas condições.

A aplicação de AS resultou em redução significativa do crescimento intrarradicular de G. intraradices e G. clarum (teste $t, \mathrm{p}<0,05$ ), em todas as épocas de avaliação (Figura 2B). Nas parcelas cultivadas em baixo $\mathrm{P}$ e que receberam AS, os níveis de colonização por G. clarum foram comparáveis aos obtidos em raizes cultivadas em condições de alto P, na ausência de AS. O efeito negativo do AS na colonização das raízes ocorreu, provavelmente, devido à inibição do crescimento fúngico intrarradicular, e não devido ao efeito inibitório nas fases de pré-infecção (germinação dos esporos, crescimento de tubos germinativos, diferenciação de apressórios), já que os níveis iniciais de colonização, em todas as situações, foram similares. O AS poderia alterar as respostas de defesa do feijoeiro, e induzir proteínas específicas, as quais controlariam o desenvolvimento do fungo nas raízes (Yalpani et al., 1991; Shirasu et al., 1997; Shulaeve et al.,1997; Silverman et al., 1993). 


\subsection{Efeito sobre as atividades de quitinases}

Plantas que receberam aplicações de 7,24 $\mu \mathrm{mol}$ de AS sobre o substrato de cultivo apresentaram, em todas as épocas de avaliação, maior atividade de quitinases no SR em relação àquelas que não receberam, cultivadas nas mesmas condições. No entanto, o grau desse aumento foi diferenciado em função da variação dos níveis dos demais fatores de

tratamento. $\mathrm{O}$ efeito de interação entre os três fatores (AS, nivel de $\mathrm{P}$, e inoculação) ocorreu com 8 e 10 SAP (tabela 3 - Apêndice 2). Tal indução já foi observada na parte aérea de várias plantas (Raskin, 1995). Embora seja de ampla aceitação a indução da síntese de proteínas relacionadas com a patogênese pelo AS (Gaffney et al., 1993; Ohashi \& Matsuoka, 1987; Yalpani et al., 1991) ainda são controvertidos os resultados sobre o mecanismo que levam a isso. A elevada concentração de AS no tecido pode ter efeito inibitório à infecção por patôgenos (Yu et al., 1997).

$\mathrm{Na}$ ausência de AS, 8 SAP, as atividades específicas de quitinases nas raízes colonizadas por $G$. intraradices ou $G$. clarum foram suprimidas, em relação aos controles não-inoculados, em condições de baixo P (teste $t, p<0,05$; Figura $3 \mathrm{~A}$ ). Em condições de alto $\mathrm{P}$, essa supressão não foi observada. Já, $10 \mathrm{SAP}$, as atividades específicas de quitinases formam induzidas em raízes colonizadas por G. clarum, em relação aos controles não-inoculados, em condições de baixo e alto $P$ (teste $t, p<0,05$; Figura 3A). As atividades de quitinases em raízes colonizadas por $G$. intraradices, 10 SAP, não diferiram dos controles não-inoculados, independentemente da concentração de $\mathrm{P}$ no substrato (teste $\mathrm{t}, \mathrm{p}<0,05$ ). Resultados semelhantes foram observados em alho, feijão e fumo (Spanu et al., 1989; Lambais \& Mehdy, 1993; David et al., 1998). Aparentemente, a regulação de quitinases ocorre na transcrição, conforme demonstrado em plantas de fumo transgênicas expressando constitutivamente uma quitinase básica com expressão diferencial em raizes micorrizadas, e o $\mathrm{P}$ atua atenuando essa supressão (Lambais \& Mehdy, 1993; David et al., 1998). 


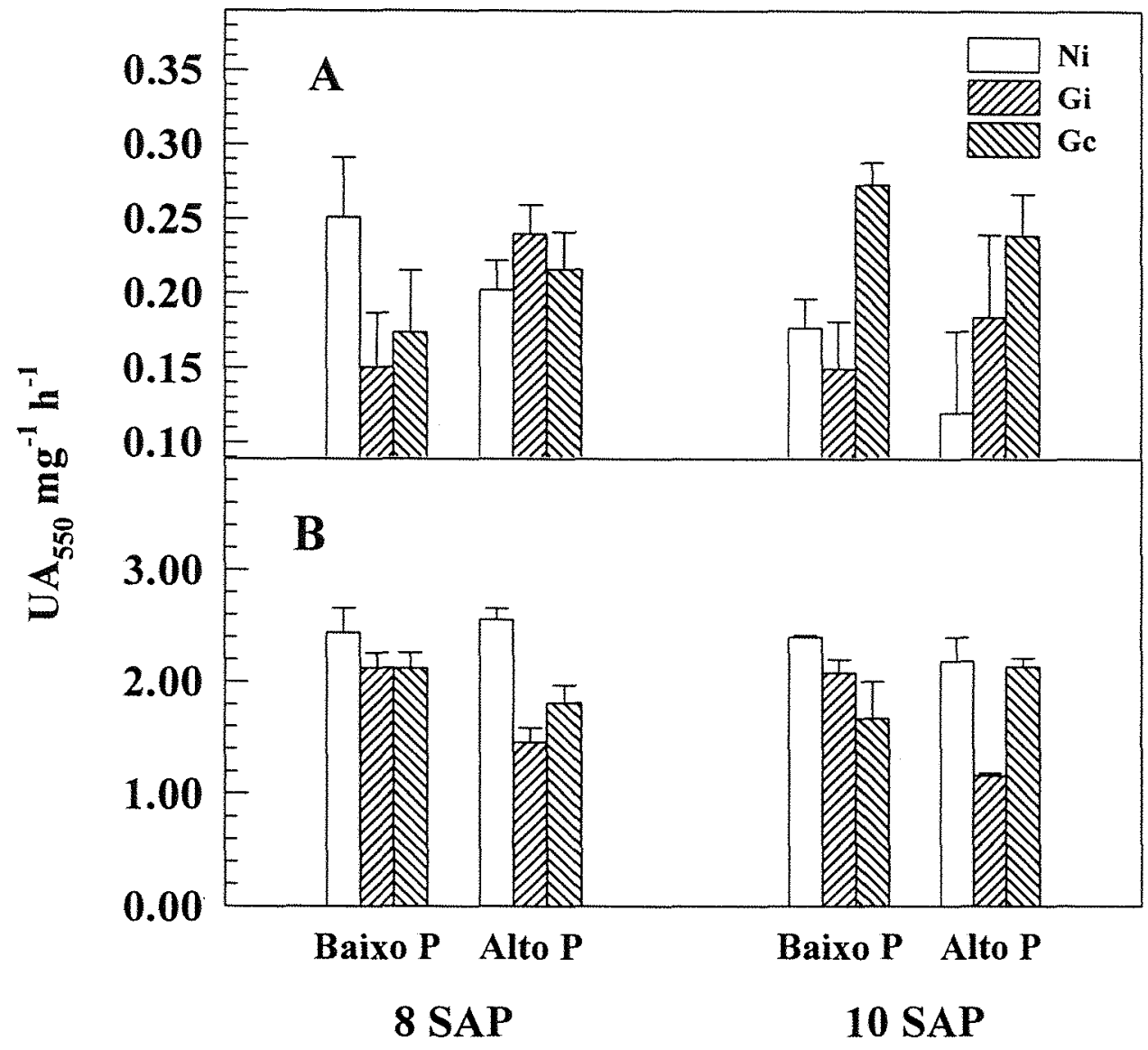

Figura 3. Atividades específicas de quitinases em raizes de feijoeiros não-inoculadas ou inoculadas com Glomus clarum (Gc) ou Glomus intraradices (Gi), em condições de baixo (32 $\mathrm{mg} \mathrm{L}^{-1}$ de substrato) ou alto P (162 $\mathrm{mg} \mathrm{L}^{-1}$ de substrato). A. Sem aplicação de ácido salicílico. B. Com aplicação de ácido salicílico $(7,24 \mu \mathrm{mol}$ a cada 2 dias, a partir de duas semanas após o plantio). Os dados são apresentados em Unidades de Absorbância à $550 \mathrm{~nm}\left(\mathrm{UA}_{550}\right)$ por mg de proteína por hora, e são médias de 4 repetições \pm desvio padrão da média. 
A aplicação de AS induziu aproximadamente 10 vezes as atividades específicas de quitinases nas raízes, em relação aos tratamentos que não receberam AS, 8 e 10 SAP específicas de quitinases, em relação ao controle não-inoculado, foi observada em raízes colonizadas por $G$. clarum, em condições de baixo P, e por $G$. intraradices em condições de alto $\mathrm{P}$ (Figura $3 \mathrm{~B}$ ). Aparentemente, a elevada atividade de quitinases nas raizes que receberam $\mathrm{AS}$, foi o fator determinante dos baixos niveis de colonização micorrízica.

Embora o papel das quitinases no controle do desenvolvimento de MAs seja desconhecido, é provável que a indução localizada de isoformas específicas iniba o crescimento fúngico intrarradicular (Lambais \& Mehdy, 1995; Lambais \& Mehdy, 1998). Normalmente, a indução de atividades de quitinases está relacionada ao aumento da resistência à infecção por fungos patogênicos (Dassi et al., 1996; Guzzo \& Martins, 1996; Mauch \& Staehelin, 1989; Pozo et al., 1996) e mecanismos semelhantes poderiam atuar em MAs. As atividades de quitinases são induzidas na parte aérea de várias plantas após a aplicação de AS em concentrações fisiológicas (Raskin, 1995). Muito embora seu mecanismo de atuação não esteja totalmente esclarecido, existem evidências mostrando que o AS interfere no estado redox das células, induzindo o acúmulo de radicais de oxigênio livres (Rao et al., 1997). Neste trabalho, os padrões de atividades de quitinases em raízes que receberam $\mathrm{AS}$, em condições de baixo $\mathrm{P}$, foram diferentes daqueles obtidos em raízes que não receberam $\mathrm{AS}$, em condições de alto $\mathrm{P}$. Muito embora os níveis de colonização de raízes inoculadas com $G$. clarum ou $G$. intraradices em condições de alto P sejam similares àqueles observados na presença de AS e condições de baixo $\mathrm{P}$, seus mecanismos de atuação são, provavelmente distintos, já que a indução de quitinases por $\mathrm{P}$ foi muito inferior à indução por AS. Seria interessante determinar quais isoformas de quitinases são reguladas pelo $\mathrm{P}$ e pelo AS e se existem isoformas que são reguladas de maneira similar na presença de AS e condições de alto P. 


\subsection{Efeito sobre as atividades $\beta-1,3$-glicanases}

Para a variável atividades de $\beta$-1,3-glicanases, também se constatou efeito de interação tripla com 8 e $10 \mathrm{SAP}$ (Tabela 3 - Apêndice 2). As atividades em plantas que receberam AS, foram quase sempre significativamente menores do que nas que não receberam (Figura 4).

Em condições de baixo P, 8 e 10 SAP, foi observada uma supressão significativa (teste $t, p<0,05$ ) das atividades específicas de $\beta$-1,3-glicanases nas raizes inoculadas com G. clarum, na ausência de $\mathrm{AS}$, em relação aos controles não-inoculados (Figura 4A). Essa supressão não foi observada em condições de alto $\mathrm{P}$, ou em raízes inoculadas com G. intraradices, em condições de baixo e alto P. Ao contrário, em raizes inoculadas com G. clarum, em condições de alto $\mathrm{P}$, houve indução significativa (teste $\mathrm{t}, \mathrm{p}<0,05$ ).

No geral, as atividades de $\beta$-1,3-glicanases nas raizes que receberam AS foram significativamente menores (teste $t, p<0,05$ ) do que nas que não receberam $A S$, independente da concentração de P, 8 e 10 SAP (Figura 4). Raízes inoculadas com $G$. intraradices apresentaram diferenças significativas em relação ao controle não-inoculado somente 10 SAP (teste $t, p<0,05$ ). Nessa época de amostragem, as atividades de $\beta-1,3-$ glicanases foram induzidas em condições de baixo $\mathrm{P}$ e suprimidas em condições de alto P (Figura 4B). Nas raízes colonizadas por G. clarum, essas atividades diferiram do controle não-inoculado somente em condições de baixo P, 8 SAP. Nessas condições, houve um incremento de $58 \%$ nas atividades especificas dessa hidrolase.

Normalmente, quitinases e $\beta$-1,3-glicanases apresentam padrões de regulação semelhantes, isto é, são co-reguladas (Vögeli et al., 1988). Neste experimento, os padrões de atividades específicas de $\beta$-1,3-glicanases diferiram daqueles observados para atividades específicas de quitinases, mostrando que, em raizes colonizadas por fungos micorrizicos arbusculares, a expressão desses genes não é co-regulada. Resultados similares foram observados por Lambais \& Mehdy (1993) em raizes de feijoeiro cultivar Tendergreen colonizadas com $G$. intraradices, com base nos padrões de atividades 


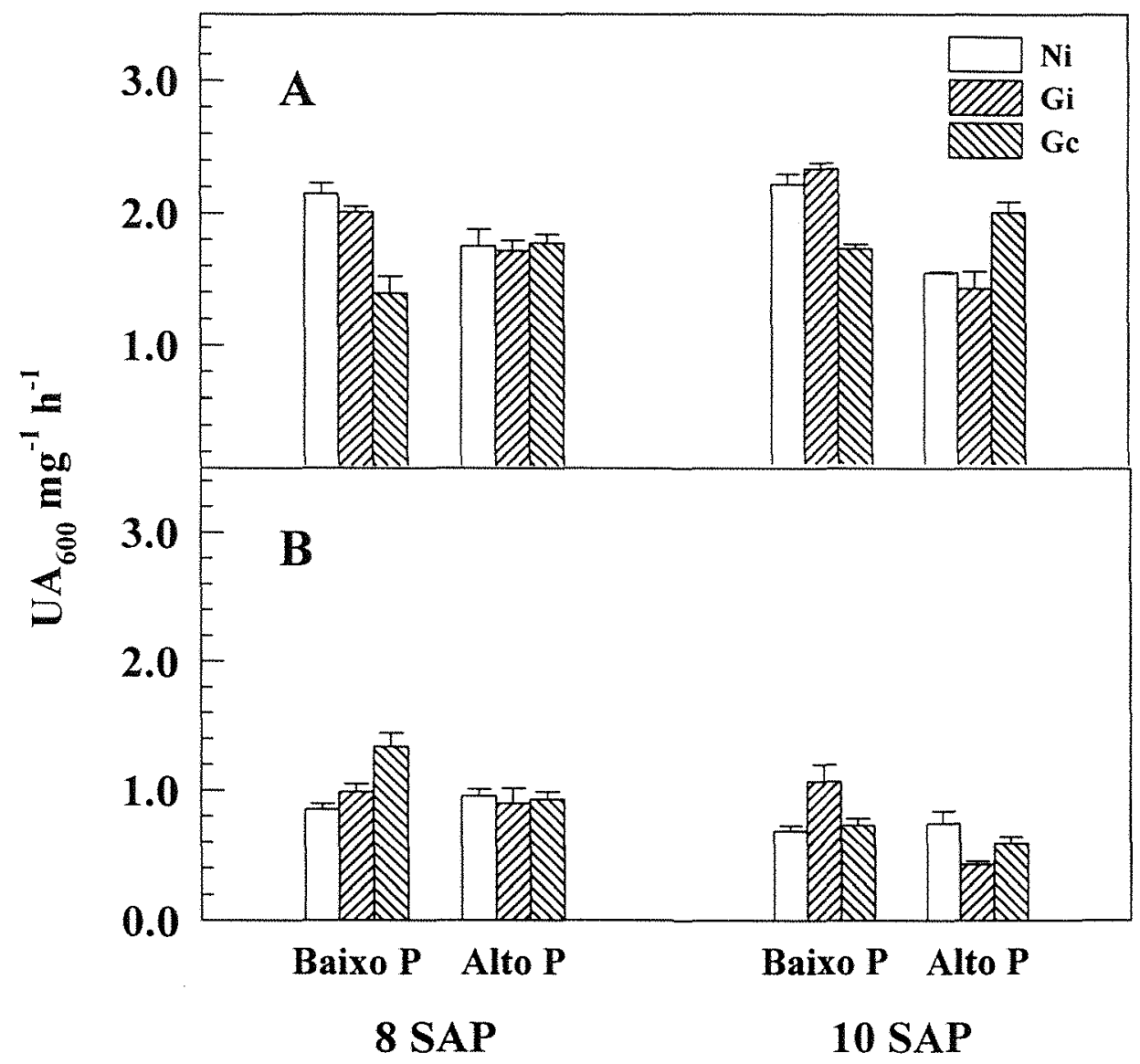

Figura 4. Atividades específicas de $\beta$-1,3-glicanases em raízes de feijoeiros nãoinoculadas ou inoculadas com Glomus clarum $(\mathrm{Gc})$ ou Glomus intraradices (Gi), em condições de baixo ( $32 \mathrm{mg} \mathrm{L}^{-1}$ de substrato) ou alto P (162 $\mathrm{mg} \mathrm{L}^{-1}$ de substrato). A. Sem aplicação de ácido salicílico. B. Com aplicação de ácido salicílico $(7,24 \mu \mathrm{mol}$ a cada 2 dias, a partir de duas semanas após o plantio). Os dados são apresentados em Unidades de Absorbância à $600 \mathrm{~nm}$ $\left(\mathrm{UA}_{600}\right)$ por mg de proteína por hora, e são médias de 4 repetições \pm desvio padrão da média. 
especificas de quitinases e $\beta$-1,3-glicanases e de acúmulo de mRNAs codificando diferentes isoformas dessas enzimas.

$\beta$-1,3-glicanases são enzimas hidrolíticas resistentes produzidas tanto por fungos quanto por plantas (Cassab \& Varner, 1988; Griffin, 1994). Presume-se que essas hidrolases estejam relacionadas aos processos de formação e alongamento da parede celular (Helleboid et al., 1998). Isoformas especificas de quitinases e $\beta$-1,3-glicanases podem também sinergisticamente atuar na degradação da parede celular de fungos fitopatogênicos (Mauch et al., 1989). No entanto, em MAs, segundo o modelo proposto por Lambais \& Mehdy (1995), a indução local de isoformas específicas de $\beta$-1,3glicanases, em condições de baixo $\mathrm{P}$, poderia contribuir para a degradação parcial da parede celular vegetal, facilitando o crescimento fúngico intrarradicular. Assim, o fato de ter-se observado supressão das atividades de $\beta$-1,3-glicanases em raízes colonizadas pelo fungo mais infectivo, G. clarum, não descarta a possibilidade da ocorrência de indução localizada de alguma isoforma específica em células. A menor colonização micorrízica em raízes que receberam AS, associada à menor atividade de $\beta$-1,3-glicanases, poderia ser explicada pelo efeito do AS no aumento da rigidez da parede celular vegetal, uma vez que ele interfere na concentração de EAOs (Allan \& Fluhr, 1997; Ohashi \& Matusuoka, 1987; Rao et al., 1997; Silverman et al.,1993; Wu et al., 1997). 


\section{CONCLUSÃO}

Os resultados obtidos mostram que o AS inibe a colonização fúngica intrarradicular, de forma semelhante à condições de alto P. No geral, o AS induziu atividades de quitinases e inibiu atividades de $\beta$-1,3-glicanases nas raízes. Os dados sugerem que os mecanismos de regulação de quitinases pelo AS e P são distintos. Os padrões de atividades de quitinases ou $\beta$-1,3-glicanases nas diferentes situações do experimento não permitem estabelecer uma relação entre atividades dessas hidrolases e colonização fúngica intrarradicular. 


\section{REFERÊNCIAS BIBLIOGRÁFICAS}

ABBOTT, L.K; ROBSON, A.D.; BOER, G. The effect of phosphorus on the formation of hyphae in soil by the vesicular-arbuscular mycorrhizal fungus, Glomus fasciculatum. The New Phytologist, v.97, n.3, p.437-446, 1984.

AGRIOS, G.N. Plant pathology London: Academic Press, 1988. 803p. Cap.5, p.97105.

AHMADJIAN, V.; PARACER, S. Symbiosis: an introduction to biological associations. Hanover: University Press of New England, 1986, 212p.

ALLAN, A.C.; FLUHR, R. Two distinct sources of elicited reactive oxigen species in tobacco epidermal cells. The plant cell, v.9, p.1559-1572, 1997.

ANTUNES, V.; CARDOSO, E.J.B.C. Growth and nutrient status of citrus plants as influenced by mycorrhiza and phosphorus application. Plant and Soil, v.131, n.1, p.11-19, 1991.

AWADE, A.; TAPIA, M.; DIDERJEAN, BURKARD, G. Biological function of bean pathogenesis-related (PR3 and PR 4) proteins. Plant Science, v.63, p.121, 1989.

AZICÓN, R.; OCAMPO, J.A. Factors affecting the vesicular-arbuscular infection and mycorrhizae dependency of thirteen wheat cultivars. The New Phytologist, v.87, n.4, p.677- 685, 1981.

BAAS, R.; LAMBERS, H. Effects of vesicular-arbuscular mycorrhizal infection and phosphate on Plantago major ssp. pleiosperma in relation to the internal phosphate concentration. Physiologia plantarum, v.74, p.701-707, 1988.

BÉCARD, G.; DOUDS, D.D.; PFEFFER, P.E. Extensive in vitro hyphal growth of vesicular-arbuscular mycorrhizal fungi in the presence of $\mathrm{CO}_{2}$ and flavonols. Applied and Environmental Microbiology, v.58, n.3, p.821-825, 1992. 
BÉCARD, G.; PICHÉ, Y. Fungal growth stimulation by $\mathrm{CO}_{2}$ and root exudates in vesicular-arbuscular mycorrhizal symbiosis. Applied and Environmental Microbiology. v.55, n.9, p.2320-2325, 1989.

BÉCARD, G.; TAYLOR, L.P.; DOUDS JR, D.D.; PFEFFER, P.E.; DONER, L.W. Flavonoids are not necessary plant signal compounds in arbuscular mycorrhizal symbioses. Molecular Plant-Microbe Interactions, v. 8, n.2, p.252-258, 1995.

BENTIVENGA, S.P.; MORTON, J.B. Systematics of Glomalean andomycorrhizal fungi: current views and future direction. In: PFLENGER, F.L.; LINDERMAN, R.G. (Ed.) Mycorrhizae and plant health. Minnesota: American Phytopathological Society, 1994. 344p. p.283-307.

BOL, J.F.; LINTHORST, H.J.M. Plant pathogenesis-related proteins induced by virus infection. Annual Review of Phytopathology, v.28, p.113-138, 1990.

BOLLER, T.; VÖGELI, U. Vacuolar localization of ethylene-induced chitinase in bean leaves. Plant Physiology, v.74, n.2, p.442-444, 1984.

BONFANTE, P. Alteration of host cell surfaces by micorrhizal fungi. In: PETRINE, O.; OULLETTE, G.B. Host wall alterations by parasitic fungi. St. Paul: APS Press, 1994. 159p. p.103-114

BONFANTE-FASOLO, P. Anatomy and morphology of mycorrhizae. In: POWELL, C.L. VA Mycorrhiza. Boca Raton: CRC press, 1984. Cap.2, p.5-33.

BONFANTE-FASOLO, P. Plant fungal interface in VA Mycorrhizal: a structural point of view. In: READ, D.J.; LEWIS, D.H.; FITTER, A.H.; ALEXANDER, I.J. (Ed) Mycorrhizas in ecosystems. Wallingford: CAB INTERNATIONAL, 1992. Part six: Physiological ecology of mycorrhizas, Cap. 45, p.340-347

BOWLES, D. Defense-related proteins in higher plants. Annual Review of Biochemistry, v.59, p.873-907, 1990.

BRADFORD, M.M. A rapid and sensitive method for the quantitation of microgram quantities of protein utilizing the principle of protein-dye binding. Analytical Biochemistry, v.72, n.1/2, p.248-254, 1976.

BULAWA, C. E. Genetics and molecular biology of chitin synthesis in fungi. Annual Review of Microbiology, v.47, p.505-534, 1993.

CASSAB, G.I.; VARNER, J.E. Cell wall proteins. Annual Review of Plant Physiology and Plant Molecular Biology, v.39, p.321, 1988. 
CHEN, Z.; SILVA, H.; KLESSIG, D.F. Active oxygen species in the induction of plant systemic acquired resistance by salicylic acid. Science, v.262, p.1883-1886, 1993.

D'AUZAC, J. L'oxygène , <<toxique >>: une défense contre les pathogenes. Plantation, Recherche, Développment. v.3, n.3, p.153-170, 1996.

DASSI ,B.; DUMAS GAUDOT, E.; ASSELIN, A.; RICHARD, C.; GIANINAZZI, S. Chitinase and $\beta$-1,3-glucanase isoforms expressed in pea roots inoculated with arbuscular mycorrhizal or pathogenic fungi. European Journal of Plant Pathology, v.102, n.1 p.105-108, 1996.

DAVID, R.; ITZHAKI, H.; GINZBERG, I.; GAFINI, Y.; GALILI, G.; KAPULNIK, Y. Suppression of tobacco basic chitinase gene expression in response to colonization by the arbuscular mycorrhizal fungus Glomus intraradices. Molecular Plant-Microbe Interactions, v.11, n.6, p.489-497, 1998.

DIXON, R.A.; HARRISON, M.J.; LAMB, C.J. Early events in the activation of plant defense responses. Annual Review of Phytopathology, v.32, p.479-501, 1994.

DUMAS-GAUDOT, E.; GRENIER, J.; FURLAN, V.; ASSELIN, A. Chitinase, chitosanase and $\beta$-1,3-glucanase activities in Allium and Pisum roots colonized by Glomus species. Plant Science. v.84, n.1, p.17-24, 1992.

DUMAS-GAUDOT, E.; SLEZACK, S.; DASSI, B.; POZO, M.J.; GIANINAZZIPEARSON, V.; GIANINZZI, S. Plant hydrolytic enzymes (chitinases and $\beta-1,3-$ glucanases) in root reactions to pathogenic and symbiotic microorganisms. Plant and Soil, v.185, p.211, 1996.

EBEL, J. Phytoalexin synthesis: the biochemical analysis of the induction process. Annual Review of Phytopathology, v.24, p,235-264, 1986.

ENYEDI, A.J.; YALPANI, N.; SILVERMAN, P.; RASKIN, I. Signal molecules in systemic plant resistance to pathogens and pests. Cell, v.70, p.879-886, 1992.

ERNST, D.; SCHRAUDNER, M.; LANGEBARTELS, C.; SANDERMANN JR., H. Ozone-induced changes of m-RNA levels of $\beta-1,3$-glucanase, chitinase and 'pathogenesis-related' protein $1 \mathrm{~b}$ in tobacco plants. Plant Molecular Biology, v.20, p.673-682, 1992.

FITTER, A. H.; MERRYWEATHER, J.W. Why are some plants more mycorrhizal than others? An ecological inquiry. In: READ, D.J.; LEWIS, D.H.; FITTER, A.H.; 
ALEXANDER, I.J. Mycorrhizas in ecosystems. Wallingford: CAB INTERNATIONAL, 1992. Part one: Status and function of vesicular-arbuscular (VA) mycorrhiza in ecosystems Cap. 3, p.26-36,

FRIESE, C.F.; ALLEN, M.F. The spread of VA mycorrhizal fungal hyphae in the soil: inoculum types and external hyphal architecture. Mycologia, v.83, n.4, p.409, 1991.

GAFFNEY, T.; FRIEDRICH, L.; VERNOOIJ, B.; et al. Requirement of Salicylic acid for the induction of systemic acquired resistance. Science, v.261, p.754-756, 1993.

GAFFNEY, T.; FRIEDRICH, L.; VERNOOIJ, B.; et al. Requirement of Salicylic acid for the induction of systemic acquired resistance. Science, v.261, p.754-756, 1993.

GERDEMANN, J.W. Vesicular-Arbuscular mycorrhiza and plant growth. Annual Review of Phytopathology, v.6, p.397-418, 1968.

GIANINAZZI-PEARSON, V. Plant cell responses to arbuscular mycorrhizal fungi: getting to roots of symbiosis. The Plant Cell, v.8, n.10, p.1871-1883, 1996.

GIANINAZZI-PEARSON, V.; BRAZANTI, B.; GIANINAZZI, S. in vitro enhancement of spore germination and early hyphal growth of vesicular arbuscular mycorrhizal fungus by host roots exudates and plant flavonoids. Symbiosis, v.7, n. , p. , 1989.

GIANINAZZI-PEARSON, V.; DUMAS-GAUDOT, E.; GOLLOTTE, A.; TAHIRIALAOUI, A.; GIANINAZZI, S. Cellular and molecular defence-related root responses to invasion by arbuscular mycorrhizal fungi. The New Phytologist, v.133, n.1, p.45-57, 1996.

GIANINAZZI-PEARSON, V.; GOLLOTTE, A.; LHERMINIER, L.; TISSERANT, B.; FRANKEN, P.; DUMAS-GAUDOT, E.; LEMOINE, M.C.; TUINEN, D.; van GIANINAZZI, S. Cellular and molecular approaches in the characterization of symbiotic events in functional arbuscular mycorrhizal associations. Canadian Journal of Botany, v.73, (supp I), s526-S532, 1995.

GIOVANNETTI, M.; MOSSE, B. An evaluation of techniques for measuring vesicular arbuscular mycorrhizal spores. The New Phytologist, v.84, n.3, p.489$500,1980$. 
GIOVANNETTI, M.; SBRANA, C.; CITERNESI, A.S.; AVIO, L. Analysis of factors involved in fungal recognition responses to host-derived signals by vesicular mycorrhizal fungi. The New Phytologist, v.133, n.1, p.65-71, 1996.

GIOVANNETTI, M.;MOSSE, B. An evaluation of techniques for measuring vesicular arbuscular mycorrhizal spores. The New Phytologist, v.84, n.3, p.489-500, 1980.

GLENN, M.G.; CHEW, F.S.; WILLIAMS, P.H. Hyphal penetration of brassica (cruciferae) roots by vesicular-arbuscular mycorrhizal fungus. New Phytologyst, v.99, n.3, p.463-472, 1985.

GRAHAM, J. H.; LEONARD, R. T.; MENGE, J.A. Membrane-mediated decrease in root exudation responsible for phosphorus inhibition of vesicular-arbuscular mycorrhizal formation. Plant Physiology, v.68, n.3, p548-552, 1981.

GRIFFIN, D. H. Fungal physiology (2ed.). New York: Wiley-Liss, 1994, 458p. Cap.3 Molecular architecture, p.63-101

GUZZO, S.D.; MARTINS, E.M.F. Local and systemic induction of $\beta$-1,3-glucanase and chitinase in coffee leaves protected against Hemileia vastatrix by Bacillus thuringiensis Journal of Phytopathology, v. 144, p. 449-454, 1996.

HARLEY, J.L.; SMITH, S.E. Mycorrhizal symbiosis. London: Academic Press, 1983

HARRISON, M.J.; DIXON, R.A. Isoflavonoid accumulation and expression of defense gene transcripts during the establishment of vesicular- arbuscular mycorrhizal associations in roots of Medicago truncatula. Molecular plant microbe interaction, v.6, n.5, p.643-654, 1993.

HASHI, Y., MATSUOKA, M. Induction and secretion of pathogenesis-related proteins by salicylate or plant hormones in tobacco suspension cultures. Plant Cell Physiology, v.28, n.4, p.573-580, 1987.

HAYMAN, D.S. The physiology of vesicular-arbuscular endomycorrhizall symbiosis. Canadian Journal of Botany, v.61, p.944-963, 1983.

HELLEBOID, S.; BAUW, G.; BELINGHERI, L.; VASSEUR, J.; HILBERT, J. -L. Extracellular $\beta$-1,3-glucanases are induced during early somatic embryogenesis in Cichorium. Planta, v.205, n.1, p.56-63, 1998. 
ISAAC, S. Fungal Plant interactions. London: Chapman\& Hall, 1992, 418p. cap. 3 Fungal-plant confrontation. p.147-207; Cap. 4 Effects of pathogenic fungal invasion on host plant physiology p.208-265, Cap. 5 Mutualistic symbioses p.266327.

JI, C.; KÚC, J. Antifungal activity of cucumber $\beta-1,3$-glucanase and chitinase. Physiological and molecular plant pathology, v.49, n.4, p.257, 1996.

JI, C.; KÚC, J. Non-host resistance to Colletotrichum lagenarium in pumpkin and squash is not primarily associated with $\beta-1,3$-glucanase and chitinase activities. Physiological and molecular plant pathology, v.50, n.6, p.361-370, 1997.

KOIDE, R.T.; SCHREINER, R.P. Regulation of the vesicular-arbuscular mycorrhizal symbiosis. Annual Review of Plant Physiology and Plant Molecular Biology, v.43, p.557-581, 1992.

KUNZE, I.; KUNZE, G.; BRÖKER, M.; MANTEUFFEL, R.; MEINS JR, F.; MÜNTZ, K. Evidence for secretion of vacuolar $\alpha$-mannosidase, class I chitinase, and cass I $\beta$-1,3-glucanase in suspension cultures of tobacco cells. Planta, v.205, n.1, p.92-99, 1998.

LAMBAIS, M. R. Aspectos bioquímicos e moleculares da relação fungo-planta em micorrizas arbusculares. In: SIQUEIRA, J. O. (Ed) Avanços em fundamentos e aplicação de micorrizas. Lavras: Universidade Federal de Lavras, 1996. 290p. cap.2, p.5-38.

LAMBAIS, M.R. MEHDY, M.C. Differential expression of defense-related genes in arbuscular arbuscular mycorrhiza. Canadian Journal of Botany., v. 73, (suppl. 1): $\mathrm{s} 533-\mathrm{s} 540,1995$.

LAMBAIS, M.R. MEHDY, M.C. Soybean roots infected by Glomus intraradices strains differing in infectivity exhibit differential chitinase and $\beta-1,3$-glucanase expression. The New Phytologist, v.134, p.531-538, 1996.

LAMBAIS, M.R. MEHDY, M.C. Suppression of endochitinase, $\beta$-1,3-glucanase, and chalcone isomerase expression in bean vesicular-arbuscular mycorrhizal roots under different soil phosphate conditions. Molecular Plant-Microbe Interactions, v.6, n.1, p.75-83, 1993.

LAMBAIS, M.R.; MEHDY, M.C. Spatial distribution of chitinases and $\beta-1,3-$ glucanase transcripts in bean arbuscular mycorrhizal roots under low and high soil phosphate conditions. The New Phytologist, v.140, n.1, p.33-42, 1998. 
LEITE, B.; RONCATO, L.D.B.; PASCHOLATI, S.F.; LAMBAIS, M.R. Reconhecimento e transdução de sinais moleculares em interações plnata-fungos patogênicos. Revisão anual de patologia de planta, v.5, p.235-280, 1997.

LEITE, B.;PASCHOLATI. Hospedeiro: alterações fisiológicas induzidas por fitopatógenos. In: BERGAMIN, F.; KIMATI, H.; AMORIN, L (Ed). Manual de fitopatologia. v.1, $3^{a}$ ed. São Paulo: Ceres, 1995. p.393-416.

MARSCHNER, H. Nutrient dynamics at the soil-root interface (Rhizosphere) In: READ, D.J.; LEWIS, D.H.; FITTER, A.H.; ALEXANDER, I.J. Mycorrhizas in ecosystems. Wallingford: CAB INTERNATIONAL, 1992, 419 p. Part one: Stsatus and function of vesicular-arbuscular (VA) mycorrhizas in ecosystem. Cap. 1, p.3-12,

MARTÍNEZ-ABARCA, F.; HERRERA-CERVERA, J. A.; BUENO, P.; SANJUAN, J.; BISSELING, T.; OLIVARES, J. Involvement of salicylic acid in the establishment of the Rhizobium melioti-alfalfa symbiosis. Molecular PlantMicrobe Interactions, v.11, n.2, p.153-155, 1998.

MAUCH, F.; STAEHELIN, L. A. Functional implications of the subcellular localization of ethylene-induced chitinase and $\beta-1,3$-glucanase in bean leaves. The Plant Cell, v.1, n.4, p.447-457, 1989.

MILOSEVIC, N.; SLUSARENKO, A.J. Active oxygen metabolism and liginification in the hypersensitive response in bean. Physiological and Molecular Plant Pathology, v.49, n.3, p.143-158, 1996.

MOLINA, R.; MASSICOTTE, H.B.; TRAPPE, J.M. Ecological role of specificity phenomena in ectomycorrhizal plant communities: Potentials for interplant linkages and guild development. In: READ, D.J.; LEWIS, D.H.; FITTER, A.H.; ALEXANDER, I.J. Mycorrhiza in ecosystems. Wallingford: CAB INTERNATIONAL, 1992 419p. Part two:Ectomycorrhizas in temperate and boreal forest ecosystems. Cap. 45, p.341-347,

MOSSE, B. Advances in the study of vesicular-arbuscular mycorrhiza. Annual Review of Phytopathology, v.11, p.171-196, 1973.

MURPHY, P. J.; LANGRIDGE, P.; SMITH, S.E. Cloning plant genes differentially expressed during colonization of roots of Hordeum vulgare by the vesiculararbuscular mycorrhizal fungus Glomus intraradices. The New Phytologist, v.135, n.2, p291-3017, 1997. 
NEUHAUS, JM.; AHL-GOY, P.; HINZ, U.; FLORES, S.; MEINS, F. High-level expression of tobacco chitinase gene in Nicotiana sylvestris. Susceptibility of transgenic plants to Cercospora nicotianae infection. Plant Molecular Biology, v.16, n.1, p141-151, 1991.

NICHOLSON, R.L.; HAMMERSCHIMIDT, R. Phenolic compounds and their role in disease resistance. Annual Review of Phytopathology, v.30, p.369-389, 1992.

OHASHI, Y., MATSUOKA, M. Induction and secretion of pathogenesis-related proteins by salicylate or plant hormones in tobacco suspension cultures. Plant Cell Physiology, v.28, n.4, p.573-580, 1987.

PACOVSKY, R.S. Micronutrient uptake and distribution in mycorrhizal or phosphorus-fertilized soybeans. Plant and soil, v.95, n.3, p.379-388, 1986.

PASCHOLATI, S.F.. Fitopatógenos: arsenal enzimático. In: BERGAMIN FILHO, A.; KIMATI, H.; AMORIN, L. (Ed). Manual de fitopatologia. v.1, 3ed. São Paulo: Ceres, 1995.919 p p.343-363

PASCHOLATI, S.F.; LEITE, B. Hospedeiro: mecanismos de resistência. In: BERGAMIN FILHO, A.; KIMATI, H.; AMORIN, L. (Ed) Manual de fitopatologia. v.1, 3ed. São Paulo: Ceres, 1995 919p. p417-453.

PAULA, M.A.; SIQUEIRA, J.O.; PINTO, J.E.B.P.; PASQUAL, M. Germination and mycelial growth of vesicular-arbuscular mycorrhiza fungal spores in the presence of plant cell exudates and extracts in vitro. Revista-Brasileira-de-Ciência-doSolo, v.13, n.3, p.281, 1989.

PHILLIPS, J.M; HAYMAN, D.S. Improved Procedures for clearing roots and staining parasitic and vesicular-arbuscular mycorrhizal fungi for rapid assessment of infection. Transactions of the British Mycological Society v.55, n.1, p. 158-162, 1970.

PITTOCK, C.; WINMAN, J.J.; ROLFE, B.G.; The activity of a tobacco basic chitinase promotor in transgenic white clover provides insights into plant development and symbiosis. Australian Journal Plant Physiology, v.24, n.5, p.555-561, 1997.

PLEFGER, F.L.; LINDERMAN, R.G. (Ed) Mycorrhizae and plant health. St. Paul: APS Press, 1994, 344p.

POZO, M.J.; DUMAS-GAUDOT, E.; SLEZACK, S.; CORDIER, C.; et al. Induction of new chitinase isoforms in tomato roots during interactions with Glomus 
mosseae and/or Phytophthora nicotianae var parasitica. Agronomie, v.16, n.10, p.689-697, 1996.

RAO, M. V.; PALIYATH, G.; ORMROD, D. P.; MURR, D. P.; WATKINS, C. B. Influence of salicylic acid on $\mathrm{H}_{2} \mathrm{O}_{2}$-metabolizing enzymes: salicylic acid-mediate damage requires $\mathrm{H}_{2} \mathrm{O}_{2}$. Plant Physiology, v.115, n.1, p.137-149, 1997.

RASKIN, I. Role of salicylic acid in plants. Annual Review of Plant Physiology and Plant Molecular., v.43, p439-463, 1992.

RASKIN, I. Salicylic acid In: DAVIES, J. ed. Plant hormones: physiology, biochemistry and molecular biology. London: Kluwer Publishers, 1995. 781P. cap C. p.188-205.

SALUNKHE, D. K.; SHARMA, R. P.; Introduction to phytoalexins. In: SALUNKHE, D. K.; SHARMA, R. P. Mycotoxins and Phytoalexins. Boca-Raton: CRC Press, 1991. Cap.19.

SCHUBERT, A; HAYMAN, D.S. Plant growth responses to vesicular-arbuscular mycorrhiza XVI: effectiveness of different endophyte at different levels of phosphorus. The New Phytologist, v.103, n1, p.79, 1986.

SCHWAB, S.M., MENGE, J.A.; LEONARD, R.T. Quantitative and qualitative effects of phosphorus on extracts and exudates of sudangrass roots in relation to vesiculararbuscular mycorrhiza formation. Plant Physiology, v.73, n.3, p.761-765, 1983.

SCHWAB, S.M., MENGE, J.A.; TINKER, P.B. Regulation of nutrient transfer between host and fungus in vesicular-arabuscular mycorrhizal. The New Phytologist, v.117, n.3, p.387-398, 1991.

SHIRASU, K.; NAKAJIMA, H.; RAJASEKHAR, V. K.; DIXON, R. A. Salicylic acid potentiates an agonist-dependent gain control tha amplifies pathogen signals in the activation of defense mechanisms. The Plant Cell, v.9, n.2, p.261, 1997.

SHULAEV, V.; SILVERMAN, P.; RASKIN, I. Airborne signaling by methyl salicylate in plant pathogen resistance. Nature, v.385, p.718-721, 1997.

SILVERMAN, P.; NUCKLES, E.; YE, S.X.; KUC, J.; RASKIN, I. Salicylic acid, ethylene, and pathogen resistance in tobacco. Molecular Plant-Microbe Interaction, v.6, n.6, p.775, 1993. 
SIMON, L. BOUSQUET, J. LÉVESQUE, R.C.; LALONDE, M. Origin and diversification of endomycorrhizal fungi and coincidence with vascular land plants. Nature, v.363, p.67-69, 1993.

SIQUEIRA, J. O.; SYLVIA. D. M.; GIBSON, J.; HUBBELL, D. H. Spores, germination, and germ tubes of vesicular-arbuscular mycorrhizal fungi. Canadian Journal of Microbiology., v.31, n.11, p.965-972, 1985.

SIQUEIRA, J.O. Micorrizas: forma e função. In: Anais da I Reunião Brasileira Sobre Micorrizas. Lavras-MG, p.5-32, 1986.

SIQUEIRA, J.O.; FRANCO, A.A. Biotecnologia do solo: fundamentos e perspectivas. Brasília:MEC. ABEAS; Lavras: ESAL, FAEP, p.125-177. 1988.

SMITH, S.E.; GIANINAZZI-PEARSON, V Physiological interaction between symbionts in vesicular-arbuscular mycorrhizal plants. Annual review of plant physiology and plant molecular biology, v.39, p.221-244, 1988.

SMITH, S.E.; SMITH, F.A. Structure and function of the interfaces in biotrophic symbioses as they relate to nutrient transport. New Phythologist., v.114, n.1, p.1$38,1990$.

SPANU P.; BOLLER T.; LUDWIG A.; WIEMKEN A.; FACCIO A.; BONFANTEFASOLO P. Chitinase in roots of mycorrhizal Allium-porrum - regulation and localization. Planta, v.177, n.4, p.447-455, 1989.

SRIVASTAVA, M.K.; DWIVEDI, U.N. Salicylic acid modulates glutathione metabolism in Pea seedling Journal of plant physiology, v.153, n.3/4, p.409414, 1998.

STANGARLIN, J.R. Caracterização de sítios de infecção de Exserohilum turcicum (Pass.) Leonard Suggs em diferentes genótipos de milho (Zea mays L) com base nos mecanismos de defesa vegetal. Piracicaba, 1995. 93p. Dissertaçao (ms) Escola Superior de Agricultura Luiz de Queiroz.

STRACK, D.; MOCK, HP. Hydroxycinnamic acid and lignins. In: DEY, P.M.; HARBORNE, J.B. (Ed) Methods in plant biochemistry: enzymes of secondary metabolism. v.9 London: Academic Press, 1993 478p. p.45-97.

TAGU, D.; MARTIN, F. Molecular analysis of cell wall proteins expressed during the early steps of ectomycorrhiza development. New Phytologyist, v.133, n. p.73-85, 1996. 
TENHAKEN, R.; RÜBEL, C. Salicylic acid is needed in hypersensitive cell death in soybean but does not act as a catalase inhibitor. Plant physiology, v.115, n.1, p.291-298, 1997.

TESTER, M.; SMITH, S.E.; SMITH, F.A. The phenomenon of "nonmycorrhizal" plants. Canadian journal of botany, v.65, n.3, p.419-431, 1987.

TINKER, P.B.; JONES, M.D.; DURALL, D.M. A functional comparison of ecto- and endomycorrhizas. In: READ, D.J.; LEWIS, D.H.; FITTER, A.H.; ALEXANDER, I.J. Mycorrhizas in ecosystems. Wallingford: CAB INTERNATIONAL, 1992. Cap. 40, p.303-331, Part six:Physiological ecology of mycorrhizas.

TSAI, S.M.; PHILLIPS, D.A. Flavonoids release naturally from alfalfa promote development of symbiotic Glomus spores in vitro. Applied and environmental microbiology, v.57, n.5, p.1485-1488, 1991.

VÖGELI,U.;MEINS JR, F.; BOLLER, T. Co-ordinated regulation of chitinase and $\beta$ 1,3-glucanase in bean leaves. Planta, v.174, n.3, p.364-372, 1988.

WIRTH, A.; WOLF, E.R.; Dye-labeled substrates for the assay and detection of chitinase and lysozyme activity. Journal of Microbiology Methods, v.12, p.197$205,1990$.

YALPANI, N.; SILVERMAN, P.; WILSON, T.M.A.; KLEIER, D.A.; RASKIN, I. Salicylic acid is a systemic signal and an inducer of pathogenesis-related proteins in virus-infected tobacco. The Plant Cell. v.3, n.8 , p.809- 818, 1991.

YU, D.; LIU, Y.; FAN, B.; KLESSIG, D. F., CHEN, Z. Is the hig basal level of salicylic acid important for disease resistance in potato? Plant Physiology, v.115, p.343, 1997. 
APÊNDICE 1

Dados originais do experimento 
Tabela 1. Valores de massa seca da parte aérea.

\begin{tabular}{|c|c|c|c|c|c|c|c|c|c|c|}
\hline \multirow[b]{2}{*}{ Inóculo } & \multirow[b]{2}{*}{$\mathrm{P}^{* 1}$} & \multirow[b]{2}{*}{$\mathrm{R}^{* 2}$} & \multicolumn{8}{|c|}{ SEMANAS APOS O PLANTIO } \\
\hline & & & & SEM & A S & & & $\mathrm{COM}$ & A S & \\
\hline \multirow{12}{*}{$\mathrm{Ni}$} & \multirow{7}{*}{20} & & 4 & 6 & 8 & 10 & 4 & 6 & 8 & 10 \\
\hline & & 1 & 0,04 & 4,74 & 7,95 & 8,90 & 0,06 & 1,55 & 0,86 & 5,43 \\
\hline & & 2 & 0,14 & 1,16 & 7,92 & 9,25 & 0,01 & 0,83 & 0,28 & 5,54 \\
\hline & & 3 & 0,74 & 0,59 & 5,47 & 8,91 & 0,01 & 1,47 & 3,68 & 5,50 \\
\hline & & 4 & 0,08 & 1,77 & 6,39 & 7,65 & 0,05 & 0,91 & 3,93 & 5,14 \\
\hline & & 5 & 0,25 & 1,55 & 4,17 & 8,62 & 0,12 & 1,19 & 2,67 & 2,06 \\
\hline & & & & & & & & & & \\
\hline & \multirow{5}{*}{150} & 1 & 0,22 & 1,52 & 8,24 & 7,73 & 0,09 & 0,09 & 3,75 & 5,06 \\
\hline & & 2 & 0,37 & 5,51 & 9,11 & 10,93 & 0,02 & 2,36 & 5,03 & 5,35 \\
\hline & & 3 & 0,10 & 0,42 & 9,36 & 8,66 & 0,10 & 0,23 & 4,04 & 5,16 \\
\hline & & 4 & 0,21 & 2,83 & 7,52 & 8,35 & 0,08 & 0,36 & 4,75 & 5,81 \\
\hline & & 5 & 0,23 & 2,57 & 8,56 & 8,92 & 0,07 & 0,76 & 4,39 & 5,35 \\
\hline \multirow{11}{*}{$\mathrm{Gi}$} & \multirow{6}{*}{20} & 1 & 0,03 & 1,63 & 4,15 & 9,35 & 0,02 & 1,41 & 4,99 & 3,67 \\
\hline & & 2 & 0,15 & 1,08 & 2,88 & 9,25 & 0,15 & 0,4 & 4,82 & 4,4 \\
\hline & & 3 & 0,48 & 3,49 & 6,89 & 8,57 & 0,01 & 0,11 & 3,99 & 4,41 \\
\hline & & 4 & 0,08 & 1,05 & 3,78 & 7,86 & 0,12 & 1,47 & 1,9 & 4,34 \\
\hline & & 5 & 0,19 & 0,52 & 3,89 & 8,70 & 0,05 & 1,1 & 4,49 & 4,53 \\
\hline & & & & & & & & & & \\
\hline & \multirow{5}{*}{150} & 1 & 0,14 & 2,97 & 7,95 & 8,71 & 0,06 & 1,53 & 4,56 & 6,05 \\
\hline & & 2 & 0,13 & 1,88 & 8,60 & 9,26 & 0,10 & 0,26 & 5,18 & 6,46 \\
\hline & & 3 & 0,21 & 1,58 & 8,47 & 8,35 & 0,03 & 0,37 & 4,07 & 5,95 \\
\hline & & 4 & 0,02 & 2,05 & 7,32 & 10,94 & 0,11 & 1,95 & 4,49 & 5,77 \\
\hline & & 5 & 0,13 & 2,12 & 8,09 & 9,32 & 0,08 & 1,03 & 4,58 & 6,06 \\
\hline \multirow{11}{*}{$\mathrm{Gc}$} & \multirow{5}{*}{20} & 1 & 0,33 & 0,51 & 3,11 & 7,50 & 0,06 & 0,39 & 5,25 & 3,25 \\
\hline & & 2 & 0,09 & 0,45 & 7,4 & 5,12 & 0,09 & 0,63 & 3,29 & 4,3 \\
\hline & & 3 & 0,09 & 1,18 & 3,86 & 5,74 & 0,04 & 0,57 & 1,85 & 3,84 \\
\hline & & 4 & 0,21 & 4,17 & 2,78 & 10,76 & 0,05 & 0,33 & 1,37 & 5,61 \\
\hline & & 5 & 0,18 & 0,28 & 6,85 & 7,28 & 0,23 & 1,07 & 2,95 & 4,72 \\
\hline & \multirow{6}{*}{150} & & & & & & & & & \\
\hline & & 1 & 0,14 & 1,53 & 4,02 & 9,45 & 0,15 & 1,17 & 5,08 & 5,32 \\
\hline & & 2 & 0,45 & 1,09 & 8,23 & 9,99 & 0,20 & 0,15 & 1,78 & 6,47 \\
\hline & & 3 & 0,06 & 2,84 & 8,89 & 9,66 & 0,09 & 1,53 & 4,03 & 6,07 \\
\hline & & 4 & 0,14 & 1,01 & 8,09 & 10,55 & 0,14 & 1,17 & 2,74 & 5,75 \\
\hline & & 5 & 0,20 & 1,62 & 7,31 & 9,91 & 0,15 & 1,01 & 3,41 & 5,90 \\
\hline
\end{tabular}

Legenda: $\mathrm{P}^{* 1}$ : Quantidades ( $\mathrm{mg} \mathrm{L}^{-1}$ de substrato) de fósforo aplicados no substrato de cultivo; $\mathrm{R}^{* 2}$ : Número da repetição de cada tratamento. 
Tabela 2. Valores estimados de massa seca do sistema radicular.

\begin{tabular}{|c|c|c|c|c|c|c|c|c|c|c|}
\hline \multirow[b]{2}{*}{ Inóculo } & \multirow[b]{2}{*}{$\mathrm{P}^{* 1}$} & \multirow[b]{2}{*}{$\mathrm{R}^{* 2}$} & \multicolumn{8}{|c|}{ SEMANAS APOS O PLANTIO } \\
\hline & & & & SE M & A S & & & $\mathrm{COM}$ & A S & \\
\hline \multirow{12}{*}{$\mathrm{Ni}$} & \multirow{7}{*}{20} & & 4 & 6 & 8 & 10 & 4 & 6 & 8 & 10 \\
\hline & & 1 & 3,03 & 22,94 & 39,52 & 27,76 & 1,51 & 7,49 & 7,05 & 21,37 \\
\hline & & 2 & 3,31 & 5,93 & 24,06 & 24,03 & 0,74 & 4,04 & 2,73 & 27,84 \\
\hline & & 3 & 5,77 & 3,94 & 22,74 & 31,88 & 1,97 & 10,15 & 19,94 & 20,61 \\
\hline & & 4 & 3,01 & 7,47 & 23,4 & 24,44 & 0,86 & 3,89 & 10,5 & 23,43 \\
\hline & & 5 & 3,78 & 7,62 & 20,53 & 26,64 & 3,00 & 6,39 & 15,55 & 17,50 \\
\hline & & & & & & & & & & \\
\hline & \multirow{5}{*}{150} & 1 & 3,43 & 6,09 & 26,83 & 20,93 & 3,22 & 1,17 & 12,86 & 15,44 \\
\hline & & 2 & 4,30 & 19,01 & 28,16 & 24,80 & 1,89 & 10,31 & 13,66 & 17,36 \\
\hline & & 3 & 2,18 & 21,64 & 35,76 & 21,13 & 3,16 & 2,10 & 13,74 & 22,36 \\
\hline & & 4 & 3,10 & 8,70 & 20,12 & 20,30 & 2,83 & 2,18 & 14,50 & 25,48 \\
\hline & & 5 & 3,25 & 13,86 & 27,72 & 21,79 & 2,78 & 3,94 & 13,69 & 20,16 \\
\hline \multirow{11}{*}{$\mathrm{Gi}$} & \multirow{6}{*}{20} & 1 & 2,09 & 8,34 & 17,81 & 39,34 & 1,29 & 8,20 & 17,73 & 16,33 \\
\hline & & 2 & 1,93 & 4,77 & 15,72 & 32,34 & 2,82 & 1,89 & 21,01 & 22,82 \\
\hline & & 3 & 4,11 & 18,81 & 29,8 & 21,29 & 0,98 & 1,08 & 19,71 & 26,05 \\
\hline & & 4 & 1,49 & 4,11 & 17,78 & 21,98 & 2,14 & 7,53 & 12,85 & 18,50 \\
\hline & & 5 & 2,41 & 3,32 & 20,36 & 37,74 & 1,8 & 7,63 & 18,51 & 16,88 \\
\hline & & & & & & & & & & \\
\hline & \multirow{5}{*}{150} & 1 & 2,60 & 7,91 & 21,02 & 22,66 & 1,19 & 6,00 & 15,06 & 21,66 \\
\hline & & 2 & 2,10 & 5,53 & 31,40 & 18,30 & 1,75 & 1,50 & 16,52 & 19,47 \\
\hline & & 3 & 2,56 & 5,15 & 30,01 & 21,96 & 1,51 & 1,95 & 10,45 & 22,63 \\
\hline & & 4 & 2,35 & 6,73 & 19,33 & 20,96 & 2,34 & 7,41 & 13,81 & 20,78 \\
\hline & & 5 & 2,40 & 6,33 & 25,44 & 20,97 & 1,70 & 4,22 & 13,96 & 21,14 \\
\hline \multirow{11}{*}{$\mathrm{Gc}$} & \multirow{5}{*}{20} & 1 & 2,49 & 2,10 & 15,80 & 23,78 & 1,96 & 2,29 & 22,19 & 21,16 \\
\hline & & 2 & 2,15 & 3,13 & 23,61 & 24,06 & 2,09 & 2,98 & 15,83 & 18,33 \\
\hline & & 3 & 2,02 & 4,57 & 19,79 & 18,94 & 1,36 & 2,60 & 11,84 & 17,48 \\
\hline & & 4 & - & 14,45 & 13,67 & 25,00 & 1,48 & 1,93 & 8,39 & 20,03 \\
\hline & & 5 & - & 2,68 & 25,22 & 22,95 & 4,47 & 5,29 & 14,73 & 19,59 \\
\hline & & & & & & & & & & \\
\hline & \multirow{5}{*}{150} & 1 & 2,01 & 6,35 & 11,79 & 21,92 & 2,90 & 4,89 & 14,56 & 18,08 \\
\hline & & 2 & 3,34 & 4,34 & 24,22 & 22,70 & 2,96 & 1,76 & 6,77 & 17,18 \\
\hline & & 3 & 1,91 & 7,69 & 16,31 & 19,46 & 1,82 & 5,43 & 12,43 & 20,37 \\
\hline & & 4 & 1,11 & 5,55 & 17,60 & 28,33 & 2,51 & 5,31 & 14,84 & 17,00 \\
\hline & & 5 & 2,09 & 5,98 & 17,48 & 23,10 & 2,55 & 4,35 & 12,15 & 18,16 \\
\hline
\end{tabular}

Legenda: $\mathrm{P}^{* 1}$ : Quantidades ( $\mathrm{mg} \mathrm{L}^{-1}$ de substrato) de fósforo aplicados no substrato de cultivo; $\mathrm{R}^{*^{2}}$ : Número da repetição de cada tratamento. 
Tabela 3 Porcentagem de raízes colonizadas pelos fungos micorrízico inoculados.

\begin{tabular}{|c|c|c|c|c|c|c|c|c|c|c|}
\hline \multirow{3}{*}{ Inóculo } & \multirow[b]{2}{*}{$\mathrm{P}^{* 1}$} & \multirow[b]{2}{*}{$\mathrm{R}^{* 2}$} & \multicolumn{8}{|c|}{ SEMANAS APÓS O PLANTIO } \\
\hline & & & & SEM & A S & & & COM & $\mathrm{AS}$ & \\
\hline & & & 4 & 6 & 8 & 10 & 4 & 6 & 8 & 10 \\
\hline \multirow{11}{*}{ Gi } & \multirow{5}{*}{20} & 1 & 0,00 & 0,00 & 3,00 & 5,00 & 0,00 & 0,00 & 0,00 & 5,82 \\
\hline & & 2 & 0,00 & 0,00 & 2,00 & 6,00 & 0,00 & 0,00 & 0,00 & 5,11 \\
\hline & & 3 & 0,00 & 2,00 & 0,00 & 8,00 & 0,00 & 0,00 & 0,00 & 6,74 \\
\hline & & 4 & 0,00 & 3,00 & 5,00 & 5,00 & 0,00 & 0,00 & 0,00 & 4,62 \\
\hline & & 5 & 0,00 & 0,00 & 8,00 & 4,00 & 0,00 & 0,00 & 0,00 & 6,49 \\
\hline & & & & & & & & & & \\
\hline & \multirow{5}{*}{150} & 1 & 0,00 & 0,00 & 0,00 & 0,00 & 0,00 & 0,00 & 0,00 & 0,00 \\
\hline & & 2 & 0,00 & 2,00 & 0,00 & 0,00 & 0,00 & 0,00 & 0,00 & 0,00 \\
\hline & & 3 & 0,00 & 1,00 & 2,00 & 0,00 & 0,00 & 0,00 & 2,00 & 0,00 \\
\hline & & 4 & 0,00 & 0,00 & 2,00 & 0,00 & 0,00 & 0,00 & 2,00 & 0,00 \\
\hline & & 5 & & & & & & & & \\
\hline \multirow{11}{*}{$\mathrm{Gc}$} & \multirow{5}{*}{20} & 1 & 0,00 & 0,00 & 32,90 & 77,00 & 0,00 & 0,00 & 0,00 & 9,83 \\
\hline & & 2 & 0,00 & 0,00 & 34,60 & 78,00 & 0,00 & 0,00 & 9,54 & 63,62 \\
\hline & & 3 & 0,00 & 15,00 & 38,80 & 77,00 & 0,00 & 0,00 & 0,00 & 13,30 \\
\hline & & 4 & 0,00 & 3,00 & 29,70 & \multirow[t]{2}{*}{72,00} & 0,00 & 0,00 & 0,00 & 17,96 \\
\hline & & 5 & 0,00 & 5,00 & 18,10 & & 0,00 & 0,00 & 0,00 & 21,91 \\
\hline & & & & & & & & & & \\
\hline & \multirow{5}{*}{150} & 1 & 0,00 & 0,00 & 0,00 & 25,20 & 0,00 & 0,00 & 0,00 & 2,44 \\
\hline & & 2 & 0,00 & 0,00 & 8,00 & 29,70 & 0,00 & 0,00 & 0,00 & 7,60 \\
\hline & & 3 & 0,00 & 0,00 & 12,00 & 27,40 & 0,00 & 0,00 & 0,00 & 0,00 \\
\hline & & 4 & 0,00 & 0,00 & 5,00 & 29,60 & 0,00 & 0,00 & 0,00 & 0,00 \\
\hline & & 5 & & & & & & & & \\
\hline
\end{tabular}

Legenda: $\mathrm{P}^{* 1}$ : Quantidades ( $\mathrm{mg} \mathrm{L}{ }^{-1}$ de substrato) de fósforo aplicados no substrato de cultivo; $\mathrm{R}^{*^{2}}$ : Número da repetição de cada tratamento. 
Tabela 4. Valores de atividade de quitinases

\begin{tabular}{|c|c|c|c|c|c|c|c|c|c|c|}
\hline \multirow[b]{2}{*}{ Inóculo } & \multirow[b]{2}{*}{$P^{* 1}$} & \multirow[b]{2}{*}{$\mathrm{R}^{* 2}$} & \multicolumn{3}{|c|}{ SEMANAS } & \multicolumn{4}{|c|}{ APÓS O PLANTIO } & \\
\hline & & & & S E M & A S & & & $\mathrm{COM}$ & A S & \\
\hline \multirow{12}{*}{$\mathrm{Ni}$} & \multirow{7}{*}{20} & & 4 & 6 & 8 & 10 & 4 & 6 & 8 & 10 \\
\hline & & 1 & 0,28 & 0,28 & 0,29 & 0,13 & $=$ & 2,92 & 1,79 & 2,37 \\
\hline & & 2 & 0,26 & - & 0,33 & 0,18 & 2,56 & 2,75 & 2,66 & 2,44 \\
\hline & & 3 & - & - & 0,25 & 0,18 & - & 2,95 & 2,64 & 2,38 \\
\hline & & 4 & 0,26 & 0,25 & 0,14 & 0,22 & 2,31 & 2,69 & 2,67 & 2,42 \\
\hline & & 5 & - & - & - & - & - & - & - & - \\
\hline & & & & & & & & & & \\
\hline & \multirow{5}{*}{150} & 1 & - & - & 0,21 & 0,15 & 2,08 & 2,45 & 2,53 & 2,82 \\
\hline & & 2 & - & 0,20 & 0,19 & 0,16 & 1,20 & 2,47 & 2,51 & 1,90 \\
\hline & & 3 & - & 0,15 & 0,22 & 0,16 & 2,08 & 2,25 & 2,83 & 2,09 \\
\hline & & 4 & - & - & 0,19 & 0,02 & 2,00 & 2,29 & 2,34 & 1,95 \\
\hline & & 5 & - & - & - & - & - & - & - & - \\
\hline \multirow{11}{*}{ Gi } & \multirow{5}{*}{20} & 1 & - & - & 0,04 & 0,30 & 1,58 & 1,96 & 2,41 & 2,11 \\
\hline & & 2 & - & - & 0,21 & 0,10 & 1,48 & 1,89 & 2,27 & 1,88 \\
\hline & & 3 & - & - & 0,17 & 0,04 & - & 1,83 & 1,82 & 1,94 \\
\hline & & 4 & - & - & 0,18 & 0,15 & - & 1,90 & 1,99 & 2,41 \\
\hline & & 5 & - & - & - & - & - & - & - & - \\
\hline & & & & & & & & & & \\
\hline & \multirow{5}{*}{150} & 1 & - & - & 0,28 & 0,23 & 1,78 & 2,06 & 1,42 & 1,16 \\
\hline & & 2 & - & - & 0,19 & 0,25 & 2,05 & 2,45 & 1,13 & 1,20 \\
\hline & & 3 & - & - & 0,23 & 0,13 & - & 2,42 & 1,53 & 1,19 \\
\hline & & 4 & - & - & 0,26 & 0,13 & - & 2,28 & 1,74 & 1,10 \\
\hline & & 5 & - & - & - & - & - & - & - & - \\
\hline \multirow{11}{*}{$\mathrm{Gc}$} & \multirow{5}{*}{20} & 1 & - & - & 0,12 & 0,29 & 1,81 & 2,23 & 2,04 & 1,19 \\
\hline & & 2 & - & 0,19 & 0,10 & 0,28 & 1,68 & 2,18 & 2,30 & 1,25 \\
\hline & & 3 & - & - & 0,20 & 0,29 & 1,79 & 2,31 & 2,38 & 1,62 \\
\hline & & 4 & - & - & 0,28 & 0,23 & - & 2,42 & 1,76 & 2,64 \\
\hline & & 5 & - & - & - & - & - & - & - & - \\
\hline & \multirow{6}{*}{150} & & & & & & & & & \\
\hline & & 1 & - & - & 0,17 & 0,21 & 1,60 & 2,16 & 2,02 & 2,12 \\
\hline & & 2 & 0,23 & - & 0,27 & 0,20 & - & 2,11 & 1,79 & 2,35 \\
\hline & & 3 & - & 0,16 & 0,19 & 0,22 & 1,84 & 2,14 & 2,06 & 2,09 \\
\hline & & 4 & - & - & 0,24 & 0,32 & 1,77 & 2,19 & 1,37 & 2,00 \\
\hline & & 5 & - & - & - & - & - & - & - & - \\
\hline
\end{tabular}

Legenda: $\mathrm{P}^{* 1}$ : Quantidades ( $\mathrm{mg} \mathrm{L}^{-1}$ de substrato) de fósforo aplicados no substrato de cultivo; $\mathrm{R}^{*^{2}}$ : Número da repetição de cada tratamento. 
Tabela 5. Valores, de atividade de $\beta$-1,3-glicanases de cada tratamento.

\begin{tabular}{|c|c|c|c|c|c|c|c|c|c|c|}
\hline \multirow[b]{2}{*}{ Inóculo } & \multirow[b]{2}{*}{$\mathrm{P}^{* 1}$} & \multirow[b]{2}{*}{$\mathrm{R}^{* 2}$} & \multicolumn{3}{|c|}{ SEMANAS } & \multirow[t]{2}{*}{ APÓS } & \multicolumn{3}{|c|}{ O PLANTIO } & \\
\hline & & & & SE M & $\mathrm{AS}$ & & & $\mathrm{COM}$ & A S & \\
\hline \multirow{12}{*}{$\mathrm{Ni}$} & & & 4 & 6 & 8 & 10 & 4 & 6 & 8 & 10 \\
\hline & & 1 & 2,53 & 2,15 & 2,34 & 2,40 & 1,23 & 1,59 & 0,97 & 0,77 \\
\hline & & 2 & 2,98 & - & 2,02 & 2,19 & - & 1,36 & 0,79 & 0,62 \\
\hline & 20 & 3 & - & - & 2,22 & 2,21 & - & 1,48 & 0,86 & 0,62 \\
\hline & & 4 & 2,81 & 1,97 & 2,00 & 2,02 & 1,12 & 1,34 & 0,78 & 0,73 \\
\hline & & 5 & - & - & - & - & - & - & - & - \\
\hline & & & & & & & & & & \\
\hline & & 1 & - & - & 1,98 & 1,54 & 1,73 & 1,52 & 0,84 & 0,72 \\
\hline & & 2 & - & 1,64 & 1,39 & 1,53 & 1,84 & 1,42 & 0,93 & 0,62 \\
\hline & 150 & 3 & - & - & 1,82 & 1,56 & 1,96 & 1,44 & 1,10 & 0,62 \\
\hline & & 4 & - & 1,58 & 1,82 & 1,52 & 1,85 & 1,51 & 0,95 & 1,02 \\
\hline & & 5 & - & - & - & - & - & - & - & - \\
\hline \multirow{11}{*}{$\mathrm{Gi}$} & & 1 & - & - & 2,03 & 2,40 & 1,81 & 1,38 & 0,98 & 1,10 \\
\hline & & 2 & - & - & 2,05 & 2,35 & 1,70 & 1,41 & 0,81 & 0,78 \\
\hline & 20 & 3 & - & 2,01 & 2,08 & 2,20 & - & 1,38 & 1,06 & 1,18 \\
\hline & & 4 & - & - & 1,87 & 2,36 & - & 1,37 & 1,10 & 1,22 \\
\hline & & 5 & - & - & - & - & - & - & - & - \\
\hline & & & & & & & & & & \\
\hline & & 1 & - & - & 1,68 & 1,28 & 1,99 & 1,80 & 1,16 & 0,48 \\
\hline & & 2 & - & - & 1,53 & 1,80 & 2,11 & 2,08 & 0,91 & 0,38 \\
\hline & 150 & 3 & - & - & 1,77 & 1,25 & - & 1,74 & 0,59 & 0,46 \\
\hline & & 4 & - & - & 1,90 & 1,35 & - & 1,87 & 0,93 & 0,39 \\
\hline & & 5 & - & - & - & - & - & - & - & - \\
\hline \multirow{11}{*}{$\mathrm{Gc}$} & & 1 & - & - & 1,47 & 1,76 & 1,80 & 1,70 & 1,21 & 0,63 \\
\hline & & 2 & - & - & 1,41 & 1,74 & - & 1,73 & 1,10 & 0,67 \\
\hline & 20 & 3 & - & - & 1,17 & 1,76 & 1,76 & 1,83 & 1,47 & 0,77 \\
\hline & & 4 & - & 1,26 & 1,52 & 1,61 & 1,78 & 1,91 & 1,56 & 0,85 \\
\hline & & 5 & - & - & - & - & - & - & - & - \\
\hline & & & & & & & & & & \\
\hline & & 1 & - & - & 1,65 & 2,13 & 1,73 & 1,39 & 0,93 & 0,47 \\
\hline & & 2 & 2,62 & - & 1,84 & 1,79 & - & 1,64 & 1,06 & 0,58 \\
\hline & 150 & 3 & - & 1,97 & 1,93 & 1,92 & 1,90 & 1,63 & 0,94 & 0,72 \\
\hline & & 4 & - & - & 1,69 & 2,13 & 1,76 & 1,19 & 0,78 & 0,58 \\
\hline & & 5 & - & - & - & - & - & - & - & - \\
\hline
\end{tabular}

Legenda: $\mathrm{P}^{* 1}:$ Quantidades ( $\mathrm{mg} \mathrm{L}^{-1}$ de substrato) de fósforo aplicados no substrato de cultivo; $\mathrm{R}^{* 2}$ : Número da repetição de cada tratamento. 
APÊNDICE 2

RESULTADOS DA ANÁLISE ESTATÍSTICA 
Tabela 1 Resultado do teste Levene de homogeneidade de variâncias $(p<0,05)$.

\begin{tabular}{ccrrrrrr}
\hline & GLT & QMT & \multicolumn{1}{c}{ SQR } & GLR & QMR & $\mathrm{Fc}$ & $(\mathrm{p}<\mathrm{Fc})^{*} 1$ \\
\hline MSPA & & & & & & & \\
4 SAP & 11 & 0,0168 & 0,2270 & 48 & 0,0047 & 3,5542 & 0,0011 \\
6 SAP & 11 & 0,8249 & 16,6008 & 48 & 0,3459 & 2,3852 & 0,0190 \\
8 SAP & 11 & 1,4524 & 26,4473 & 48 & 0,5510 & 2,6359 & 0,0101 \\
10 SAP & 11 & 2,6096 & 31,7711 & 48 & 0,6619 & 3,9425 & 0,0004 \\
MSSR & & & & & & & \\
8 SAP & 11 & 0,6889 & 23,9439 & 48 & 0,4988 & 1,3810 & 0,2126 \\
10 SAP & 11 & 0,4246 & 17,0956 & 48 & 0,3562 & 1,1923 & 0,3177 \\
NCSR & & & & & & & \\
8 SAP & 7 & 10,3874 & 56,0070 & 24 & 2,3336 & 4,4512 & 0,0027 \\
10 SAP & 7 & 152,9072 & 524,7206 & 24 & 21,8634 & 6,9938 & 0,0001 \\
AQSR & & & & & & & \\
8 SAP & 11 & 0,0419 & 0,4244 & 36 & 0,0118 & 3,5542 & 0,0019 \\
10 SAP & 11 & 0,0812 & 0,6617 & 36 & 0,0184 & 4,4181 & 0,0003 \\
AGSR & & & & & & & \\
8 SAP & 11 & 0,1012 & 0,2660 & 36 & 0,0074 & 1,3640 & 0,2289 \\
10 SAP & 11 & 0,0160 & 0,1592 & 36 & 0,0044 & 3,6226 & 0,0017 \\
\hline
\end{tabular}

Obs. Legenda valida para todas as tabelas desse apêndice. GLT: Grau de liberdade dos tratamentos; QMT: Quadrado médio de tratamentos; SQR: Soma de quadrados dos resíduos; GLR: Grau de liberdade dos resíduos; QMR: Quadrado médio dos resíduos; Fc: Coeficiente de teste calculado; *1: Probabilidade de encontra F>Fc.; SAP: Semanas após o plantio.;FV: Fator de tratamento; CV: Coeficiente de variação; AQSR: Atividades de quitinases no sistema radicular; AGSR: Atividades de $\beta$-1,3-glicanases no sistema radicular; NC: Nivel de Colonização intraradicular pelos fungos inoculados; 
Tabela 2 Resumo das análises de variâncias das variáveis MSPA e MSSR das UE's do experimento 5 .

\begin{tabular}{|c|c|c|c|c|c|c|c|}
\hline \multirow[b]{3}{*}{ FV } & \multirow[b]{3}{*}{ GL } & \multicolumn{6}{|c|}{ QM DE CADA VARIÁVEL POR ÉPOCA DE COLHEITA } \\
\hline & & \multicolumn{4}{|c|}{ MSPA } & \multicolumn{2}{|c|}{ MS S R } \\
\hline & & 4 SAP & 4 SAIA & 8 SAP & 10 SAP & $8 \mathrm{SAP}$ & 10 SAP \\
\hline \multirow[t]{2}{*}{ AS } & 1 & 0,1804 & 13,3576 & 121,6951 & 205,0540 & 57,8771 & 33,9994 \\
\hline & & $(0,001)$ & $(0,001)$ & $<(0,001)$ & $<(\mathbf{0 , 0 0 1 )}$ & $<(0,001)$ & $<(0,001)$ \\
\hline \multirow[t]{2}{*}{ NP } & 1 & 0,0001 & 1,0428 & 49,0149 & 22,8906 & 0,1102 & 0,0773 \\
\hline & & $(0,939)$ & $(0,663)$ & $<(0,001)$ & $<(\mathbf{0 , 0 0 1 )}$ & $(0,778)$ & $(0,725)$ \\
\hline \multirow[t]{2}{*}{ FG } & 2 & 0,0095 & 1,1819 & 3,1412 & 0,3092 & 3,9870 & 1,7214 \\
\hline & & $(0,528)$ & $(0,351)$ & $(0,252)$ & $(0,733)$ & $(0,068)$ & $(0,069)$ \\
\hline \multirow[t]{2}{*}{$A S^{*} N P$} & 1 & 0,0089 & 0,7775 & 8,9012 & 0,1060 & 0,5585 & 0,2152 \\
\hline & & $(0,557)$ & $(0,590)$ & $(0,048)$ & $(0,742)$ & $(0,540)$ & $(0,564)$ \\
\hline \multirow[t]{2}{*}{$\mathrm{AS} * \mathrm{FG}$} & 2 & 0,0172 & 0,5065 & 8,4275 & 0,2053 & 3,6326 & 1,7207 \\
\hline & & $(0,313)$ & $(0,640)$ & $(0,029)$ & $(0,812)$ & $(0,086)$ & $(0,069)$ \\
\hline \multirow[t]{2}{*}{$\mathrm{NP} * \mathrm{FG}$} & 2 & 0,0049 & 0,1145 & 0,5387 & 3,4689 & 1,5900 & 0,0809 \\
\hline & & $(0,722)$ & $(0,901)$ & $(0,788)$ & $(0,035)$ & $(0,086)$ & $(0,877)$ \\
\hline \multirow[t]{2}{*}{$\mathrm{AS} * \mathrm{NP} * \mathrm{FG}$} & 2 & 0,0009 & 0,4108 & 2,0961 & 1,6762 & 0,7815 & 7,1111 \\
\hline & & $(0,979)$ & $(0,696)$ & $(0,602)$ & $(0,181)$ & $(0,585)$ & $<(0,001)$ \\
\hline Residuo & 48 & 0,0145 & 1,1029 & 2,2199 & 0,9709 & 1,4178 & 0,6148 \\
\hline CV $(\%)$ & - & 86,263 & 75,818 & 29,616 & 14,162 & 37,557 & 21,964 \\
\hline
\end{tabular}

Obs. São válidas todas as considerações cabíveis já feitas na tabela anterior. Aplicou-se test ' $t$ 'para comparar os efeitos dos fatores e suas interaçð̃es em todas as análises desse experimento.

Tabela 3 Resumo das análises de variâncias (QM e probabilidade para valor de $\mathrm{F}$ superior ao calculado) das demais variáveis analisadas no experimento.

\begin{tabular}{|c|c|c|c|c|c|c|c|}
\hline \multirow[b]{3}{*}{$\mathrm{FV}$} & \multirow[b]{3}{*}{ GL } & \multicolumn{6}{|c|}{ QM DE CADA VARIÁVEL POR ÉPOCA DE COLHEITA } \\
\hline & & \multicolumn{2}{|c|}{ AQS R } & \multicolumn{2}{|c|}{ AGSR } & \multicolumn{2}{|c|}{$\mathrm{NC}^{*} 1$} \\
\hline & & 8 SAP & $10 \mathrm{SAP}$ & $8 \mathrm{SAP}$ & 10 SAP & 8 SAP & $10 \mathrm{SAP}$ \\
\hline \multirow[t]{2}{*}{ AS } & 1 & 42,2532 & 35,8183 & 7,7876 & 16,1518 & 908,4453 & 3042,000 \\
\hline & & $<(\mathbf{0 , 0 0 1 )}$ & $<(\mathbf{0 , 0 0 1 )}$ & $<(0,001)$ & $<(0,001)$ & $<(\mathbf{0 , 0 0 1 )}$ & $<(\mathbf{0 , 0 0 1 )}$ \\
\hline \multirow[t]{2}{*}{ NP } & 1 & 0,2014 & 0,1753 & 0,1612 & 1,3635 & 540,3828 & 3280,500 \\
\hline & & $(0,044)$ & $(0,096)$ & $(0,017)$ & $<(0,001)$ & $<(\mathbf{0 , 0 0 1 )}$ & $<(\mathbf{0 , 0 0 1 )}$ \\
\hline \multirow[t]{2}{*}{$\mathrm{FG}$} & $2 / 1$ & 0,5940 & 0,4311 & 0,0190 & 0,0115 & 717,2578 & 7062,662 \\
\hline & & $<(0,001)$ & $(0,003)$ & $(0,503)$ & $(0,571)$ & $<(0,001)$ & $<(\mathbf{0 , 0 0 1 )}$ \\
\hline \multirow[t]{2}{*}{$A S * N P$} & 1 & 0,2966 & 0,1243 & 0,0028 & 0,1094 & 395,5078 & 254,251 \\
\hline & & $(0,016)$ & $(0,160)$ & $(0,744)$ & $(0,023)$ & $<(\mathbf{0 , 0 0 1 )}$ & $(0,090)$ \\
\hline \multirow[t]{2}{*}{$A S^{*} F G$} & $2 / 1$ & 0,4898 & 0,5095 & 0,3913 & 0,0055 & 548,6328 & 2635,380 \\
\hline & & $<(0,001)$ & $(0,001)$ & $<(\mathbf{0 , 0 0 1 )}$ & $(0,763)$ & $<(\mathbf{0}, \mathbf{0 0 1})$ & $<(\mathbf{0}, \mathbf{0 0 1})$ \\
\hline \multirow[t]{2}{*}{ NP*FG } & $2 / 1$ & 0,1031 & 0,4357 & 0,0342 & 0,7126 & 374,6953 & 1946,880 \\
\hline & & $(0,128)$ & $(0,003)$ & $(0,284)$ & $<(0,001)$ & $<(\mathbf{0 , 0 0 1 )}$ & $<(\mathbf{0 , 0 0 1 )}$ \\
\hline \multirow[t]{2}{*}{$\mathrm{AS} * \mathrm{NP} * \mathrm{FG}$} & $2 / 1$ & 0,2121 & 0,5326 & 0,4556 & 0,3310 & 255,9453 & 341,914 \\
\hline & 48 & $(0,018)$ & $(0,001)$ & $<(0,001)$ & $<(\mathbf{0}, 001)$ & $<(0,001)$ & $(0,051)$ \\
\hline Resíduo & 24 & 0,0476 & 0,0615 & 0,0263 & 0,0198 & 9,5120 & 83,200 \\
\hline C. V. $(\%)$ & - & 19,075 & 23,264 & 11,626 & 10,942 & 52,081 & 49,826 \\
\hline
\end{tabular}

Legenda $*_{1}$ : Variável analisada com apenas dois niveis do fator Fungo micorrizico. Valem as demais considerações cabíveis já feitas em tabelas anteriores. 